\title{
BMJ Open Risk of invasive candidiasis with prolonged duration of ICU stay: a systematic review and meta-analysis
}

\author{
Zhidan Zhang, Ran Zhu, Zhenggang Luan, Xiaochun Ma
}

To cite: Zhang Z, Zhu R, Luan Z, et al. Risk of invasive candidiasis with prolonged duration of ICU stay: a systematic review and meta-analysis. BMJ Open 2020;10:e036452. doi:10.1136/ bmjopen-2019-036452

- Prepublication history and additional material for this paper are available online. To view these files, please visit the journal online (http://dx.doi. org/10.1136/bmjopen-2019036452).

Received 11 September 2019 Revised 12 March 2020 Accepted 13 March 2020
Check for updates

(C) Author(s) (or their employer(s)) 2020. Re-use permitted under CC BY-NC. No commercial re-use. See rights and permissions. Published by BMJ.

Department of Critical Care Medicine, The First Hospital of China Medical University, Shenyang, China

Correspondence to Dr Xiaochun Ma; XCMA2972@sina.com

\section{ABSTRACT}

Objective This study aimed to evaluate the duration of intensive care unit (ICU) stay prior to onset of invasive candidiasis (IC)/candidaemia.

Design Systematic review and meta-analysis.

Data sources PubMed, Cochrane, Embase and Web of Science databases were searched through June 2019 to identify relevant studies.

Eligibility criteria Adult patients who had been admitted to the ICU and developed an IC infection.

Data extraction and synthesis The following data were extracted from each article: length of hospital stay, length of ICU stay, duration of ICU admission prior to candidaemia onset, percentage of patients who received antibiotics and duration of their antibiotic therapy prior to candidaemia onset, and overall mortality. In addition to the traditional meta-analyses, meta-regression was performed to explore possible mediators which might have contributed to the heterogeneity.

Results The mean age of patients ranged from 28 to 76 years across selected studies. The pooled mean duration of ICU admission before onset of candidaemia was 12.9 days ( $(95 \% \mathrm{Cl} 11.7$ to 14.2$)$. The pooled mean duration of hospital stay was $36.3 \pm 5.3$ days $(95 \% \mathrm{Cl}$ 25.8 to 46.7$)$, and the pooled mean mortality rate was $49.3 \% \pm 2.2 \%$ (95\% Cl $45.0 \%$ to $53.5 \%$ ). There was no significant difference in duration of hospital stay $(p=0.528)$ or overall mortality $(p=0.111)$, but a significant difference was observed in the mean length of ICU stay (2.8 days, $\mathrm{p}<0.001$ ), between patients with and without Candida albicans. Meta-regression analysis found that South American patients had longer duration of ICU admission prior to candidaemia onset than patients elsewhere, while those in Asia had the shortest duration.

Conclusions Patients with IC are associated with longer ICU stay, with the shortest duration of ICU admission prior to the candidaemia onset in Asia. This shows a more proactive strategy in the diagnosis of IC should be considered in caring for ICU patients.

\section{INTRODUCTION}

Candida species account for approximately $70 \%-90 \%$ of invasive fungal infections and are the most frequent cause of fungal infections in patients admitted to the intensive care unit (ICU). ${ }^{1}$ Invasive candidiasis (IC) is associated with a high mortality rate (range: $40 \%-60 \%) .{ }^{12}$ Over recent decades, the

\section{Strengths and limitations of this study}

- This meta-analysis is one of the few that investigated the association of invasive candidiasis with length of intensive care unit (ICU) stay, using data published worldwide and adhering to the Preferred Reporting Items for Systematic Reviews and MetaAnalyses guideline.

- Extensive subgroup analyses were performed and meta-regression was made to examine possible causes of heterogeneity in the results.

- Although this meta-analysis was performed methodically, it lacked a prespecified protocol and preliminary registration.

- Heterogeneity exists in some subgroup and overall analyses.

- Due to a lack of sufficient published data, relationship between prolonged exposure to broadspectrum antibiotics and ICU-acquired candidaemia could not be assessed.

incidence of IC has been gradually increasing in most regions, ${ }^{3}$ ranging from 0.5 to 32 cases per 1000 ICU admissions. It has been found that there is a significant difference in the incidence of IC among several countries in Latin America and North America; however, data from Asia Pacific countries are still relatively rare. ${ }^{4}$ Candidaemia has been described as the most common manifestation of IC, and further infection of the liver, spleen, heart valves or eye might also occur after a bloodstream infection. ${ }^{5}$ In the past, the main Candida species isolated from patients with IC was Candida albicans. However, non-C. albicans species have seen a rising proportion and now account for approximately $50 \%$ of all cases of IC in the past two decades. ${ }^{16-8}$

Diagnosis and management of IC remain challenging for physicians in the ICU. ${ }^{2}$ The early initiation of empiric antifungal treatment has been demonstrated to improve the prognosis of IC. ${ }^{29}$ However, there is difficulty in the diagnosis of IC, which can delay timely antifungal treatment. ${ }^{210}$ Blood culture 
remains the gold standard for the diagnosis of IC, but its sensitivity is variable $(21 \%-71 \%) .{ }^{11}$

To improve the diagnosis of IC and to identify the patients who may best benefit from prophylactic, preemptive or empiric therapy prior to or at an early stage of ICU admission, several methods in predicting the development of IC based on their associated risk factors have been developed. ${ }^{12} 13$ The risk factors in the various predictive models include broad-spectrum antibiotic use, central venous catheter placement, total parenteral nutrition, haemodialysis (days 1-3 in the ICU), any surgery, immunosuppressive use, pancreatitis prior to ICU admission and steroid use. However, different risk factors are included in different predictive models. In addition, potential risk factors such as Candida colonisation ${ }^{14}$ and mechanical ventilation ${ }^{15}$ have not been included in these models.

Long-term ICU stay has been reported as a risk factor for IC. ${ }^{114-16}$ Only a few studies have examined the interval between ICU admission or initiation of broad-spectrum antibiotics and the diagnosis of IC. However, the specific duration of long-term ICU stays and the prolonged use of broad-spectrum antibiotics are often arbitrarily defined and inconsistent among studies. ${ }^{6} 1215$ 17-19 Furthermore, a large majority of severe candidiasis cases are caused by endogenous colonisation. This may be the primary reason for causing a delay of $7-10$ days between exposure to risk factors and the development of $\mathrm{IC}^{20}$

Thus, the objective of this systematic review was to evaluate several possible risk factors associated with the development of candidaemia, including the length of hospitalisation and ICU stay, as well as regional differences in these factors.

\section{METHODS}

\section{Search strategy}

The study was performed in accordance with guidance from the Preferred Reporting Items for Systematic Reviews and Meta-Analyses. PubMed, Cochrane, Embase and Web of Science databases were searched from inception through June 2019 using the following terms: candidiasis, candidemia, intensive care unit or ICU, and risk factors (online supplementary table S1). Studies identified by the search strategy were reviewed for inclusion and data were extracted by two independent reviewers. Where there was uncertainty regarding study eligibility, a third reviewer was consulted. A flow chart of the study selection is shown in figure 1 .

\section{Study selection criteria}

Randomised controlled trials, cohort studies, casecontrolled and cross-sectional studies were included. All studies included adult patients who were critically ill, who had been admitted to the ICU and who were tested positive for Candida species using blood culture analyses. Studies had to have reported quantitative outcomes of interest, and no author was contacted. Letters, comments,
Records identified through database search: PubMed $(\mathrm{n}=581)$, Embase $(n=566)$, Cochrane $(n=42)$, Web of Science $(n=677)$, and manual search $(n=9)$, and after duplicates were removed $(\mathrm{n}=1875)$

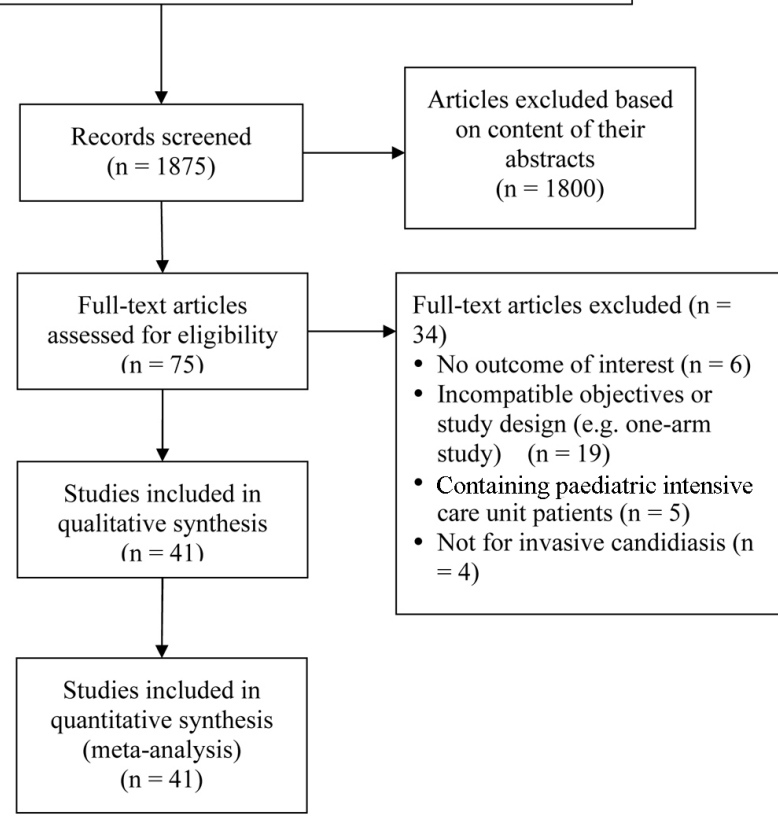

Figure 1 PRISMA flow diagram of study selection. PRISMA, Preferred Reporting Items for Systematic Reviews and MetaAnalyses.

editorials, case reports, proceedings, personal communications and case series were excluded. Studies in which patients were diagnosed with candidiasis prior to ICU admission were excluded. Studies that did not evaluate the incidence of candidiasis as a primary objective or that were not designed to evaluate risk factors/prognostic factors of patients with candidiasis were also excluded.

\section{Data extraction}

The following information/data were extracted from studies that met the inclusion criteria: name of the first author, year of publication, country, study design, type of ICU, number of participants in each group, participants' age and gender, presence of C. albicans, presence of neutropaenia and antifungal treatment (especially the use of broad-spectrum antibiotics). The following data were also extracted from each article: length of stay in hospital/ ICU, length of stay prior to ICU admission, duration of ICU stay prior to candidaemia onset, antibiotic therapy prior to candidaemia onset, duration of antibiotic therapy prior to candidaemia onset and overall mortality.

\section{Quality assessment}

We used the Risk of Bias In Non-randomized Studies of Interventions (ROBINS-I) tool to assess the quality of the included studies. ${ }^{21}$ ROBINS-I is based on the Cochrane Risk of Bias tool and is suited for evaluating nonrandomised studies that compare the health effects of different interventions. ROBINS-I covers seven different bias domains: bias due to confounding, bias in selection 
of participants into the study, bias in classification of interventions, bias due to deviations from intended interventions, bias due to missing data, bias in measurement of outcomes and bias in the selection of reported results. ${ }^{22}{ }^{23}$ In this systematic review, two independent reviewers performed the quality assessment, with a third reviewer consulted for any uncertainty.

\section{Patient and public involvement}

No patients and/or members of the public were involved in the process of designing, planning and completing this study.

\section{Statistical analysis}

Study characteristics were summarised as mean $\pm \mathrm{SD}$, mean (range), median (range) or median (IQR) for age or duration of antifungal treatment, and percentage for sex, rate of C. albicans isolated, neutropaenia and antifungal treatment used in each study.

Clinical outcomes, including length of hospital stay, length of ICU stay, length of hospital stay prior to ICU admission, duration of ICU admission prior to candidaemia onset and duration of antibiotic therapy prior to candidaemia onset, were represented as mean (range: min-max), median (range) or median (IQR: first to third quartiles). The rate of antibiotic therapy prior to candidaemia onset and overall mortality rate were presented as percentages. All clinical outcomes were further summarised for subgroups of studies (with number of studies $\geq 2$ ). Types of study, presence of neutropaenia, types of ICU, type of Candida isolated, presence of IC/candidaemia and regions/countries were listed for comparison as well. Meta-regression analyses were performed to investigate statistical importance of potential moderators. Quantitative data reported with median (range) and/or median IQR were converted to mean $\pm \mathrm{SD}$, according to the method described by Wan $e t a^{24}$

The outcomes selected for the analysis were length of hospital stay, length of ICU stay, duration of ICU admission prior to candidaemia onset and overall mortality between patients who were diagnosed with $C$. albicans and those with non-C. albicans. The effect size was calculated as the mean difference with 95\% CI (lower limit, upper limit) in length of days, or rate ratio with $95 \%$ CI in overall mortality for each given study, and a pooling effect was derived thereafter. A difference in the mean of length in days $<0$ (or rate ratio of overall mortality rate $>1$ ) indicated the pooling effect favouring non-C. albicans subgroup, whereas a difference in the mean of length in days $>0$ (or rate ratio of overall mortality rate $<1$ ) indicated the pooling effect favouring C. albicans subgroup. A difference in the mean of length in days $=0$ (or rate ratio of overall mortality rate $=1$ ) indicated that the pooling effect was similar between C. albicans and non-C. albicans subgroups. Heterogeneity was evaluated using $\chi^{2}$-based Cochran's $Q$ statistic and $I^{2}$. The random-effect model (DerSimonian-Laird method) and meta-regression analyses with potential moderators were used for the meta-analysis if either $\mathrm{Q}$ statistic with $\mathrm{p}$ values is $<0.10$ or $\mathrm{I}^{2}$ is $>50 \%$; otherwise, a fixed-effect model (Mantel-Haenszel method) was used. For the $Q$ statistic, $p$ values $<0.10$ were considered statistically significant for heterogeneity. For the $\mathrm{I}^{2}$ statistic, heterogeneity was assessed as follows: no heterogeneity $\left(\mathrm{I}^{2}=0 \%-25 \%\right)$, moderate heterogeneity $\left(\mathrm{I}^{2}=25 \%-50 \%\right)$, large heterogeneity $\left(\mathrm{I}^{2}=50 \%-75 \%\right)$ and extreme heterogeneity $\left(\mathrm{I}^{2}=75 \%-100 \%\right)$. A two-sided $\mathrm{p}$ value of $<0.05$ was considered statistically significant.

Countries were grouped based on their continents, but since meta-analysis of this particular topic has not yet been seen in China, research articles from China will be separately examined and discussed.

Publication bias was assessed using the funnel plot with Egger's test and the classic fail-safe $\mathrm{N}$ test for all enrolled studies (except for subgroups). The absence of publication bias was indicated by the data points forming a symmetric funnel-shaped distribution and a one-tailed significance level of p>0.05 in an Egger's test. ${ }^{25}$ All analyses were performed using Comprehensive Meta-Analysis V.3.3.070 statistical software (Biostat, Englewood, New Jersey, USA).

\section{RESULTS}

\section{Literature search results}

A total of 1875 articles were retrieved from the databases, and 1800 articles were excluded after their titles and abstracts were screened based on the inclusion/exclusion criteria (figure 1). Seventy-five articles underwent full-text review, and 34 articles were excluded for having irrelevant objectives or study designs $(n=19)$, containing patients in neonatal or paediatric ICU $(n=5)$, not having IC $(n=4)$ and not reporting outcomes of interest $(n=6)$. The remaining 41 articles were included in the systematic review and meta-analysis.

\section{Study characteristics}

The characteristics of the 41 studies are summarised in (tables 1 and 2). ${ }^{14-16}$ 26-29 30-63 A total of 10692 patients were included in these studies, with the number of patients in each study ranging from 12 to 1400 . The mean age of the patients ranged from 28 to 76 years, and majority were male (range: $20 \%-75.9 \%$ ). These studies were conducted in different countries, with 19 in Europe, 14 in Asia, 1 in the USA, 4 in South America, 2 in Australia and 1 multinational study (Australia, Belgium, Greece and Brazil).

Among studies that reported the mean length of ICU admission being $\leq 10$ days prior to candidaemia onset, including the early-onset group in the study by Yang et $a l^{26}$ and the Flu-S group in the study by Liao et $a l,{ }^{14}$ the overall mortality ranged from $28.6 \%$ to $70.0 \%$ (table 2). Among studies that reported the median length of ICU admission being $>10$ days prior to candidaemia onset, the overall mortality ranged from $40.8 \%$ to $44.8 \%$.

Similar to other countries, most patients with IC in China received antibiotic treatment prior to candidaemia 


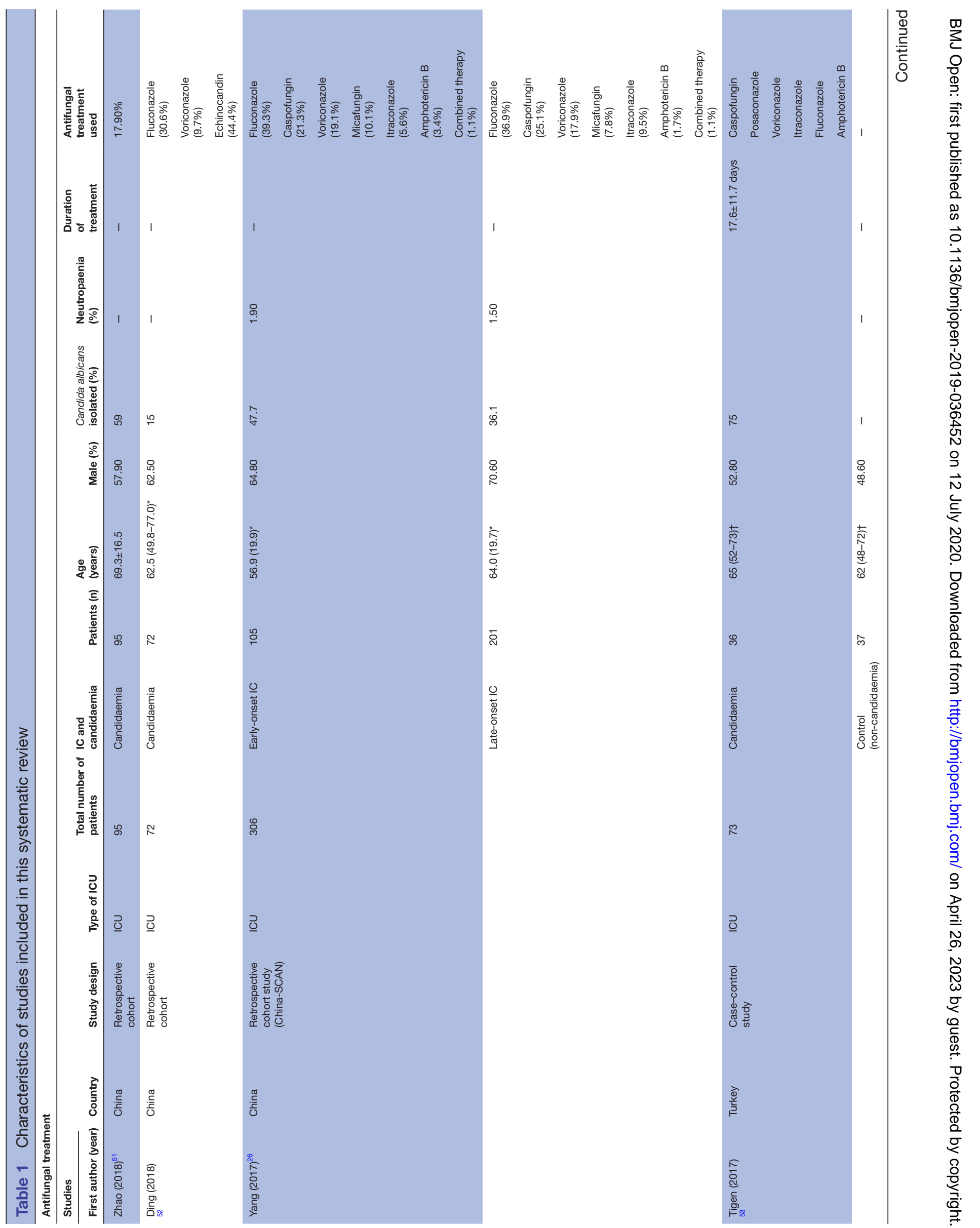




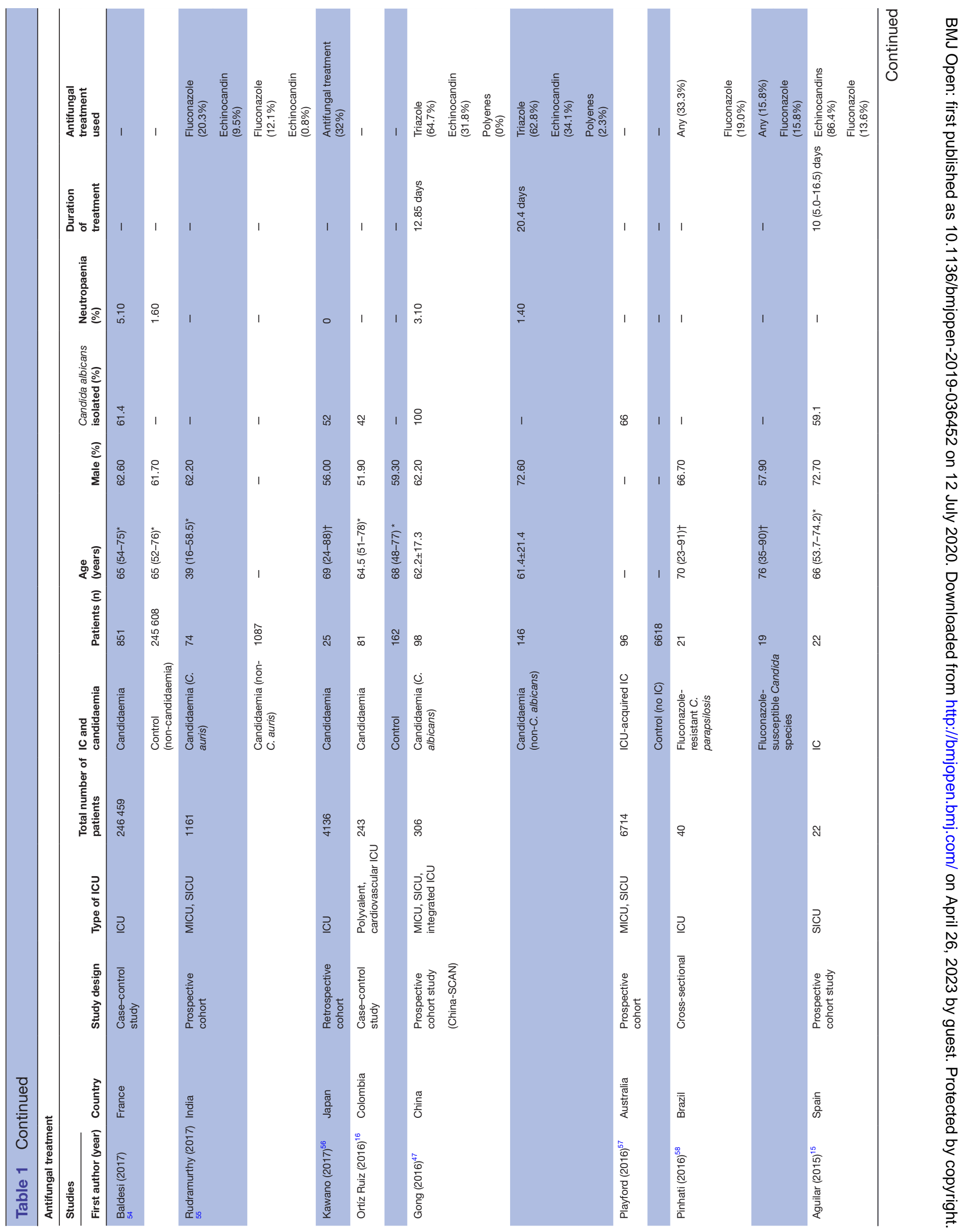




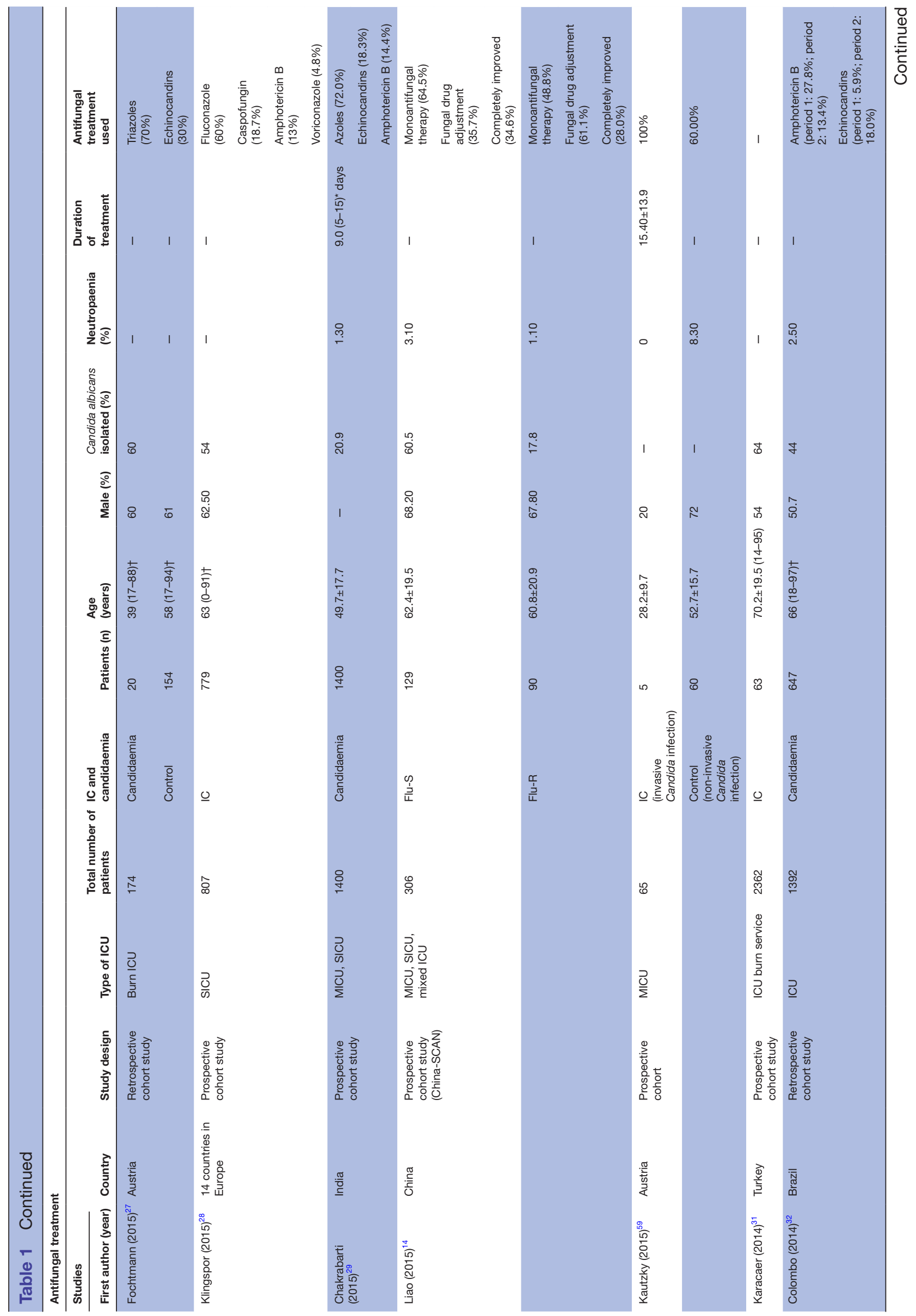

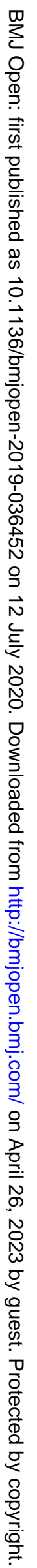




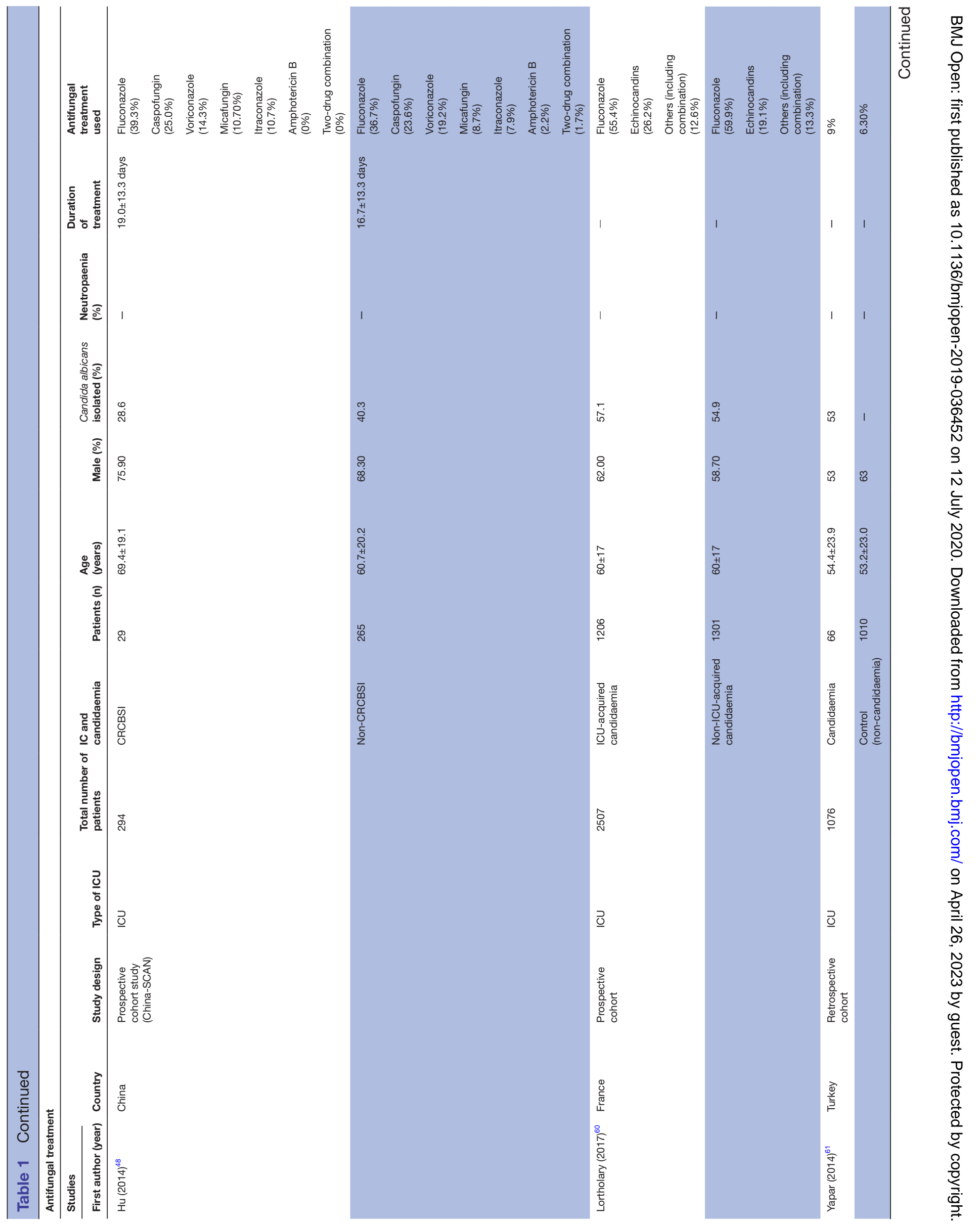




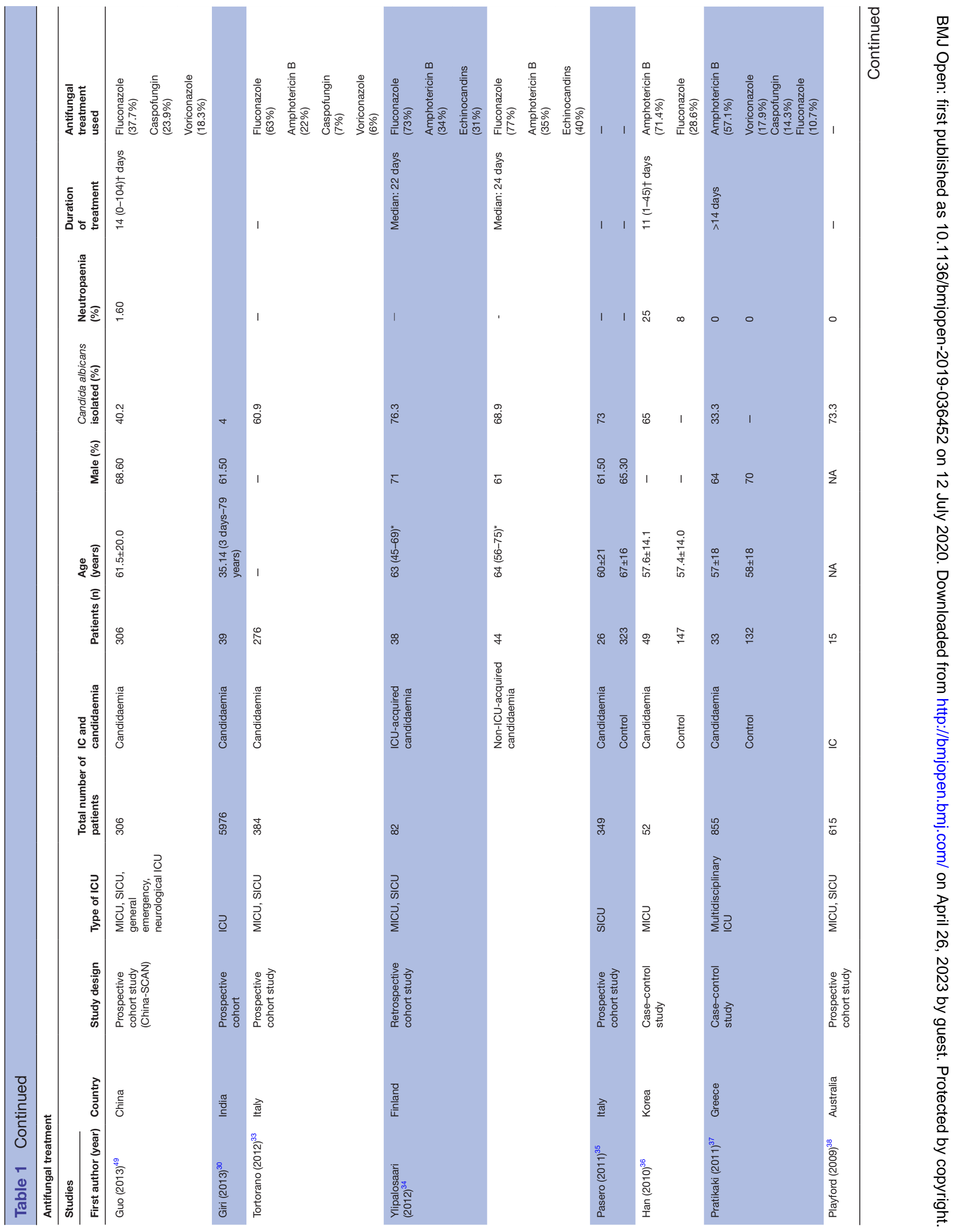




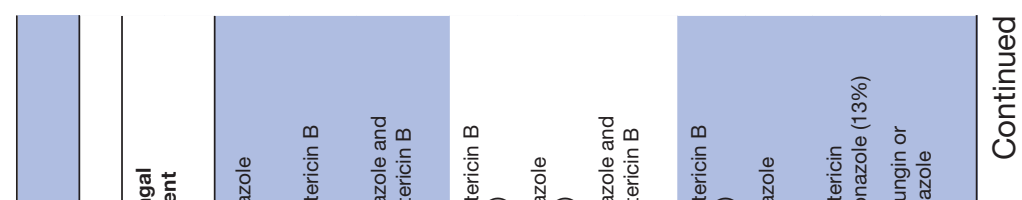

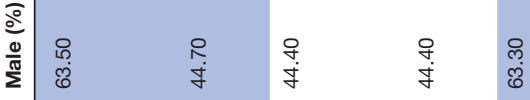

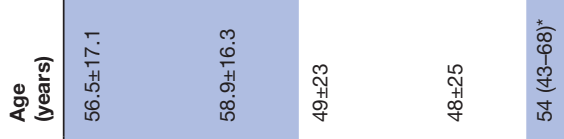
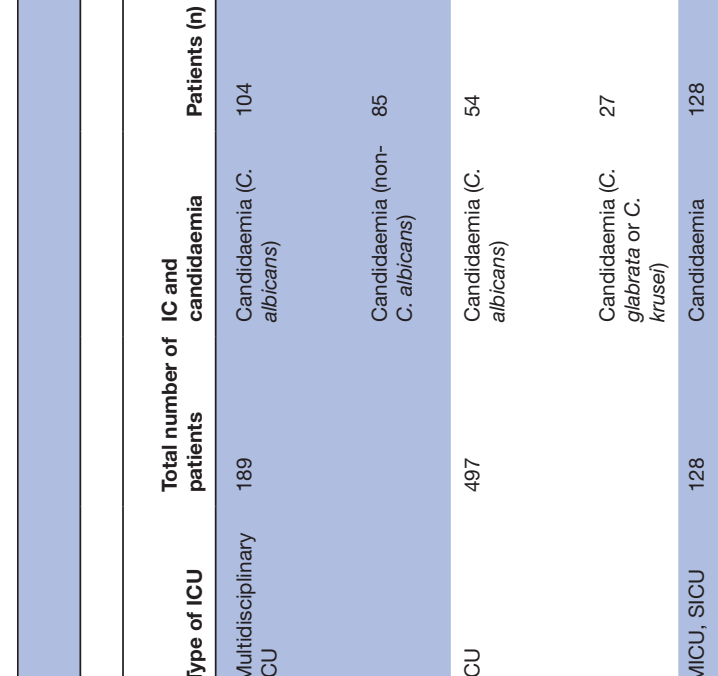

字

$\stackrel{\infty}{\sim}$

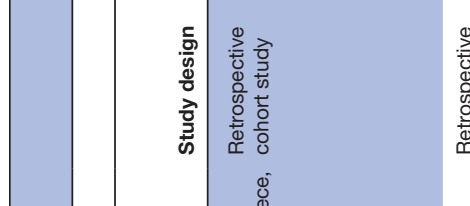

$\underline{\mathrm{O}}$

$\frac{\frac{2}{2}}{\frac{0}{0}}$
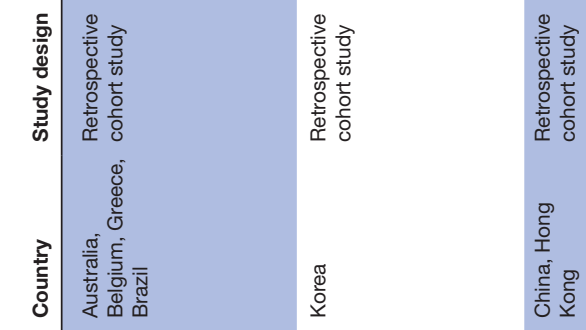


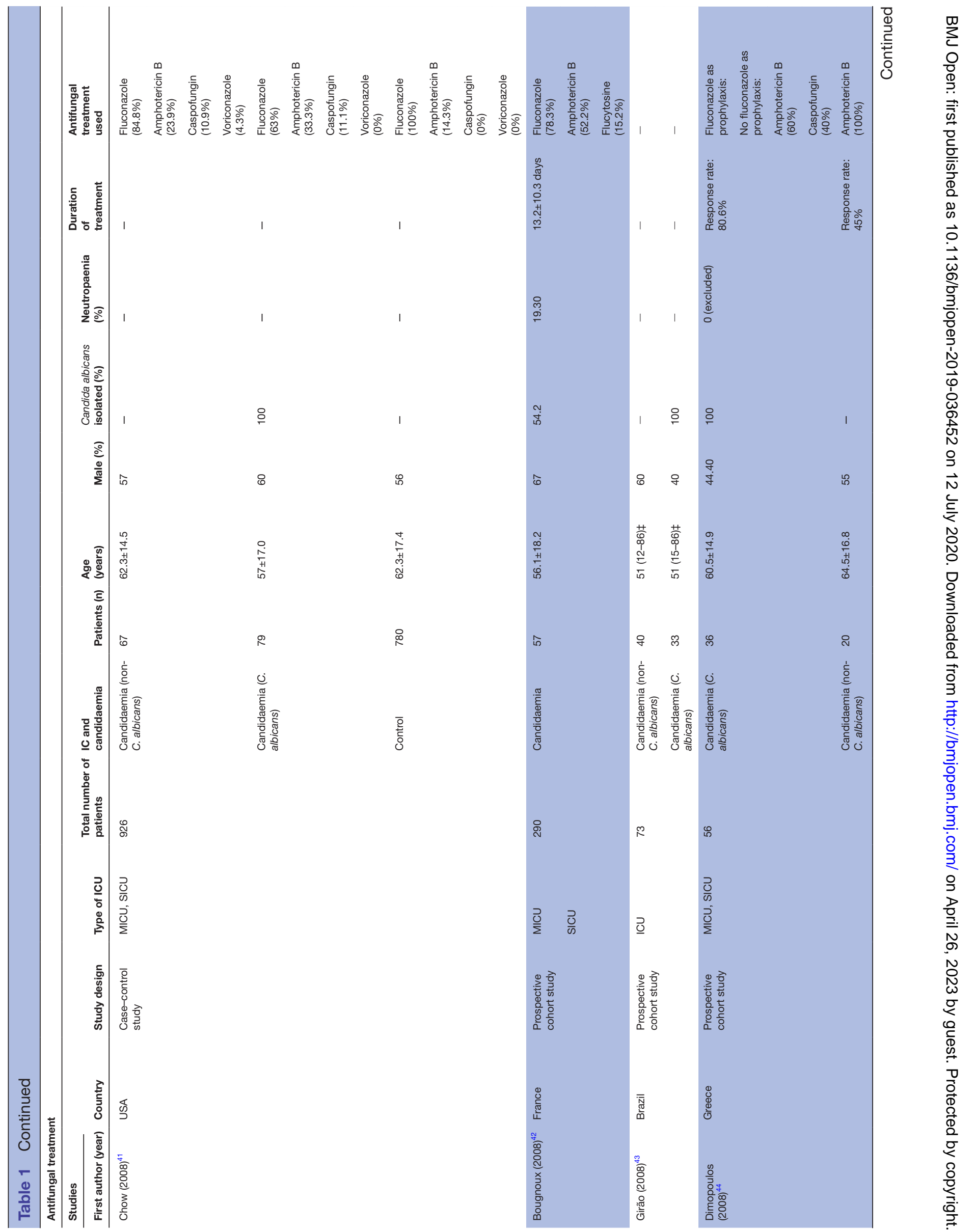




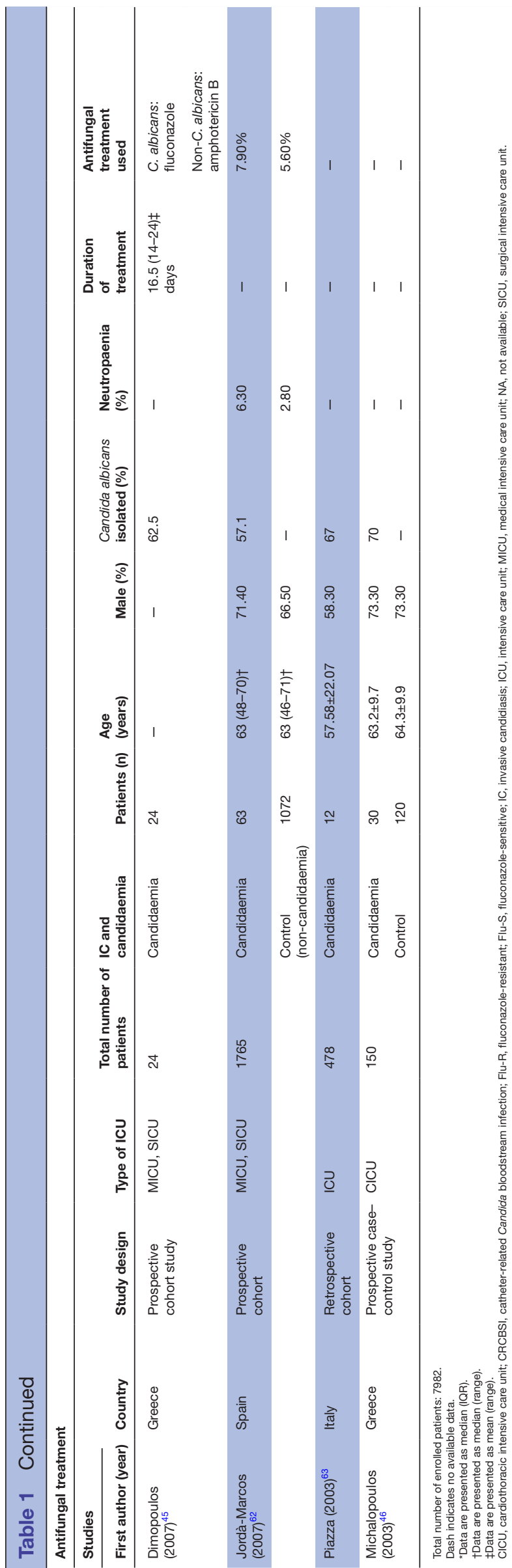

onset in the ICU, which ranged from $59.0 \%$ in the earlyonset group $^{26}$ to $100 \%$ in the catheter-related Candida bloodstream infection (CRCBSI) and non-C. albicans groups. ${ }^{491}$ Only one study reported the median duration of antibiotic therapy prior to candidaemia onset, which ranged from 10.6 to 11.4 days. ${ }^{49}$

\section{Meta-analysis}

Summary of the clinical outcomes for overall studies or given subgroups

The summary of variables such as length of hospital stay, length of ICU stay, duration of ICU admission prior to candidaemia onset, length of hospital stay prior to ICU admission and overall mortality is presented in table 3 . Five studies ${ }^{14} 26$ 47-49 were from China, using China-SCAN patient data, in which four studies were excluded to avoid overlapping data.

Across all studies, the mean length of hospital stay, mean length of ICU stay, mean duration of ICU admission prior to candidaemia onset, mean length of hospital stay prior to ICU admission and mean overall mortality rate were found to be 36.3 days (95\% CI 25.8 to 46.7), 25.8 days (95\% CI 23.6 to 28.1 ), 12.9 days (95\% CI 11.7 to 14.2$), 11.7$ days (95\% CI 0.37 to 23.1$)$ and $49.3 \%$ (95\% CI $45.0 \%$ to $53.5 \%$ ), respectively. After four China-SCAN studies were excluded from the analysis, the mean length of hospital stay, mean length of ICU stay, mean duration of ICU admission prior to candidaemia onset and the mean overall mortality rate were found to be 37.5 days (95\% CI 33.3 to 41.6 ), 25.9 days (95\% CI 23.5 to 28.3 ), 13.7 days (95\% CI 12.5 to 15.0 ) and $50.99 \%$ (95\% CI $46.6 \%$ to $55.4 \%$ ), respectively (table 3 ).

Other outcomes including types of study, presence of neutropaenia, types of ICU, types of C. albicans isolated, presence of IC/candidaemia and regions/countries were also summarised for subgroups of studies (with studies' number $\geq 2$ ). The interval estimate showed the summarised statistics of subgroups were all significant except for length of hospital stay of patients with IC, length of hospital stay prior to ICU admission of patients selected from retrospective or cross-sectional type of studies, and patients with candidaemia (95\% CI included 0) (table 3).

According to the summarised statistics in table 3, patients with neutropaenia had longer length of hospital stay (mean=34.9 vs 22.9 days), longer duration of ICU admission prior to candidaemia onset (mean $=11.6$ vs 10.0 days) and higher overall mortality rate (rate: $49.6 \%$ vs $41.3 \%$ ) than non-neutropaenic patients. The mean durations of ICU admission prior to candidaemia onset were 17.3 days, 17 days, 14.3 days and 10.9 days for patients in surgical ICU (SICU), medical ICU (MICU), ICU and MICU+SICU, respectively. Patients with candidaemia had longer length of hospital stay (mean=36.3 vs 33.9), longer duration of ICU admission prior to candidaemia onset (mean=13.2 vs 11.5 ) and higher overall mortality rate $(51.4 \%$ vs $38.9 \%)$ than patients without IC. However, patients with candidaemia had shorter length of ICU stay 


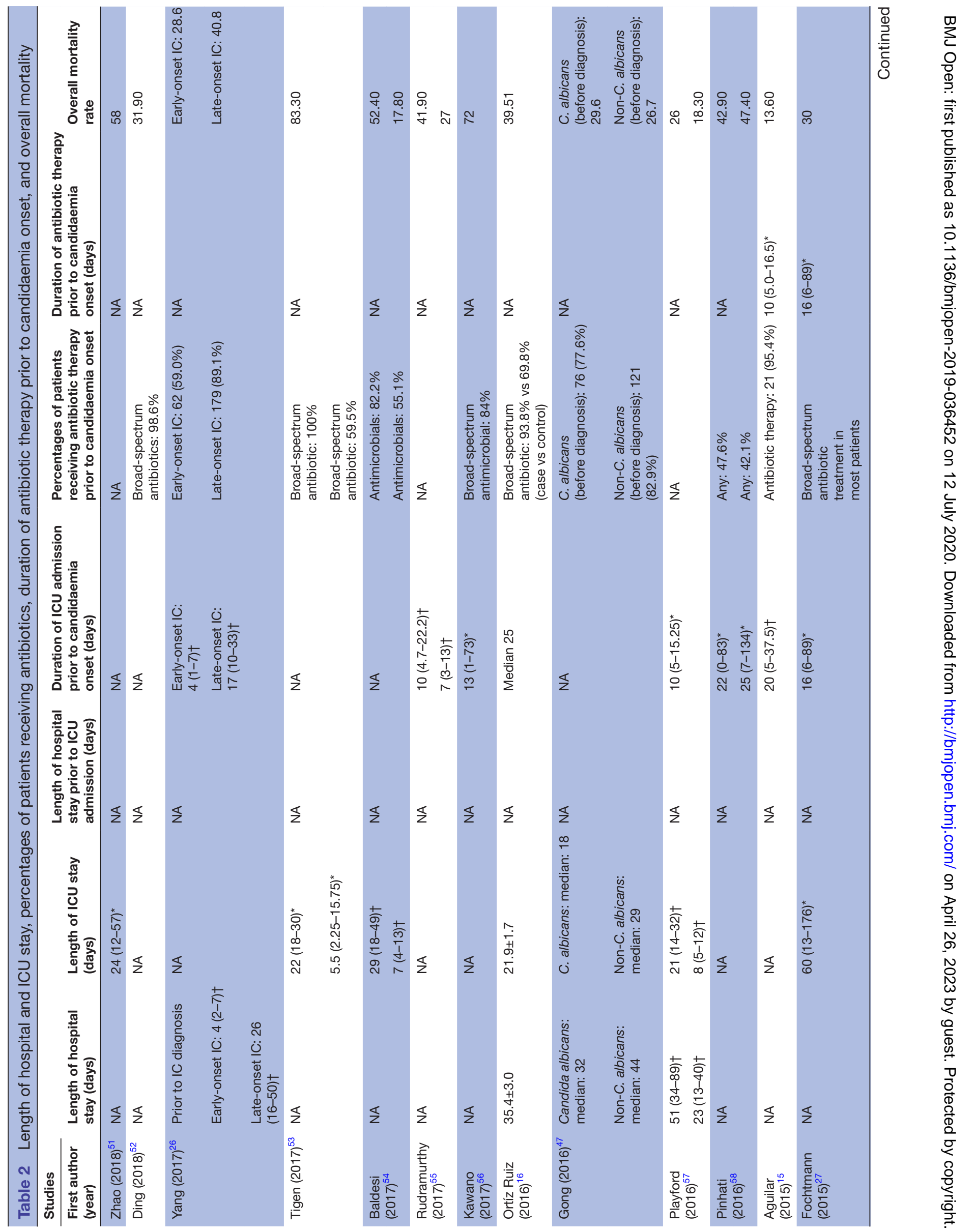



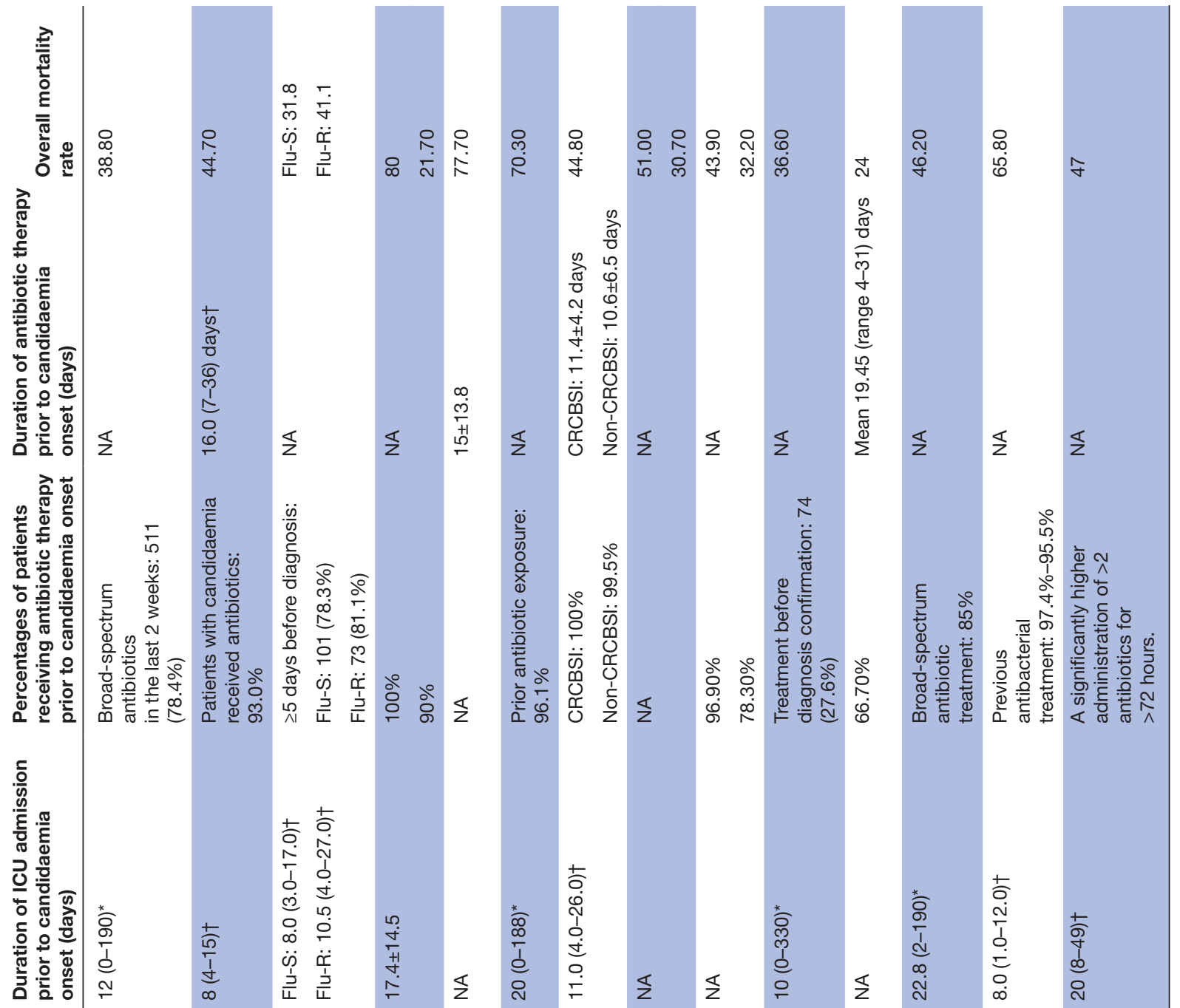

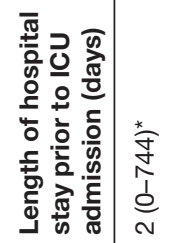

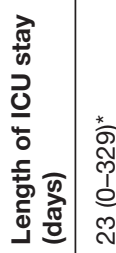

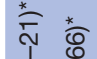

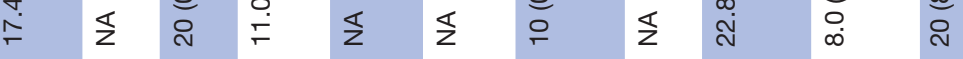
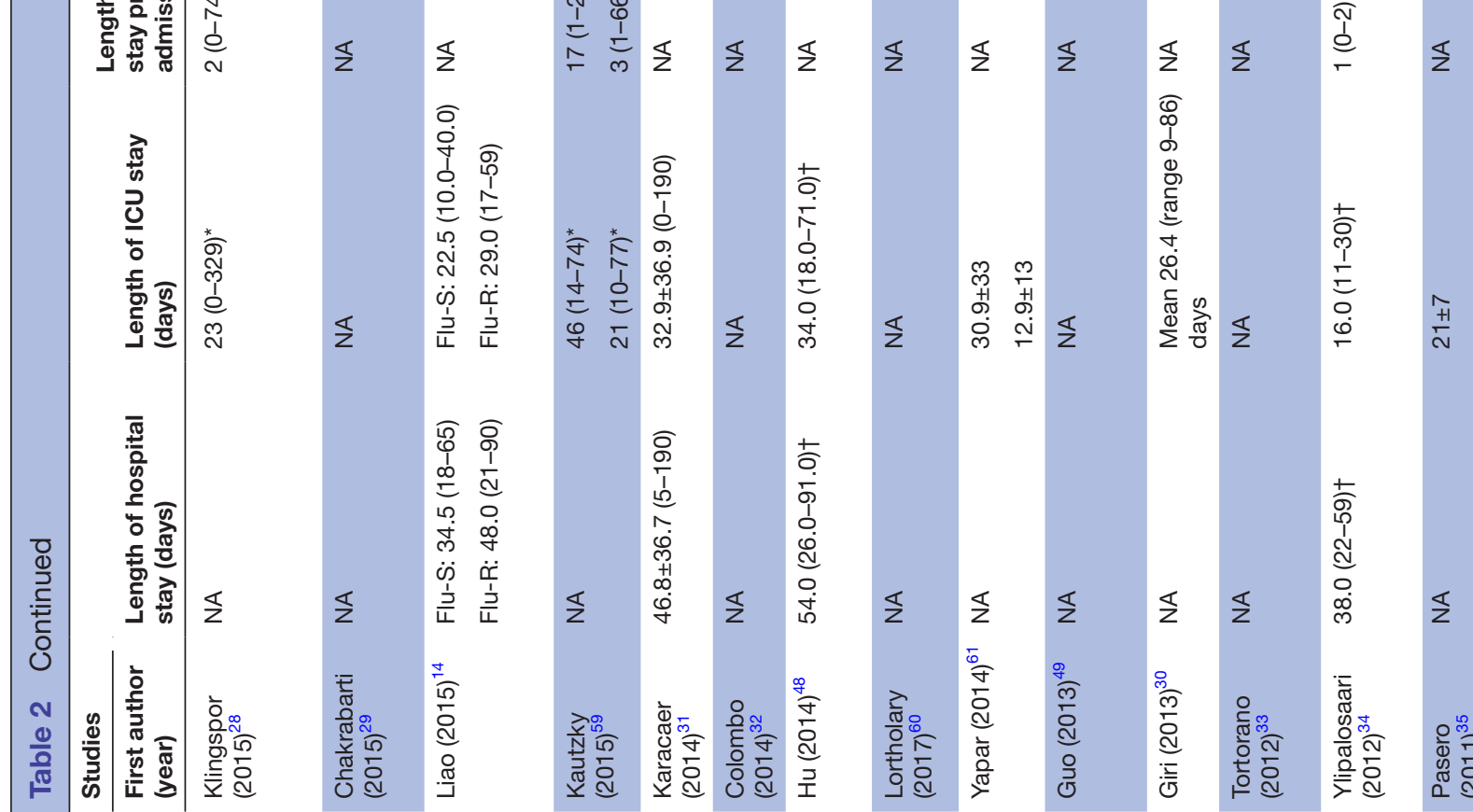


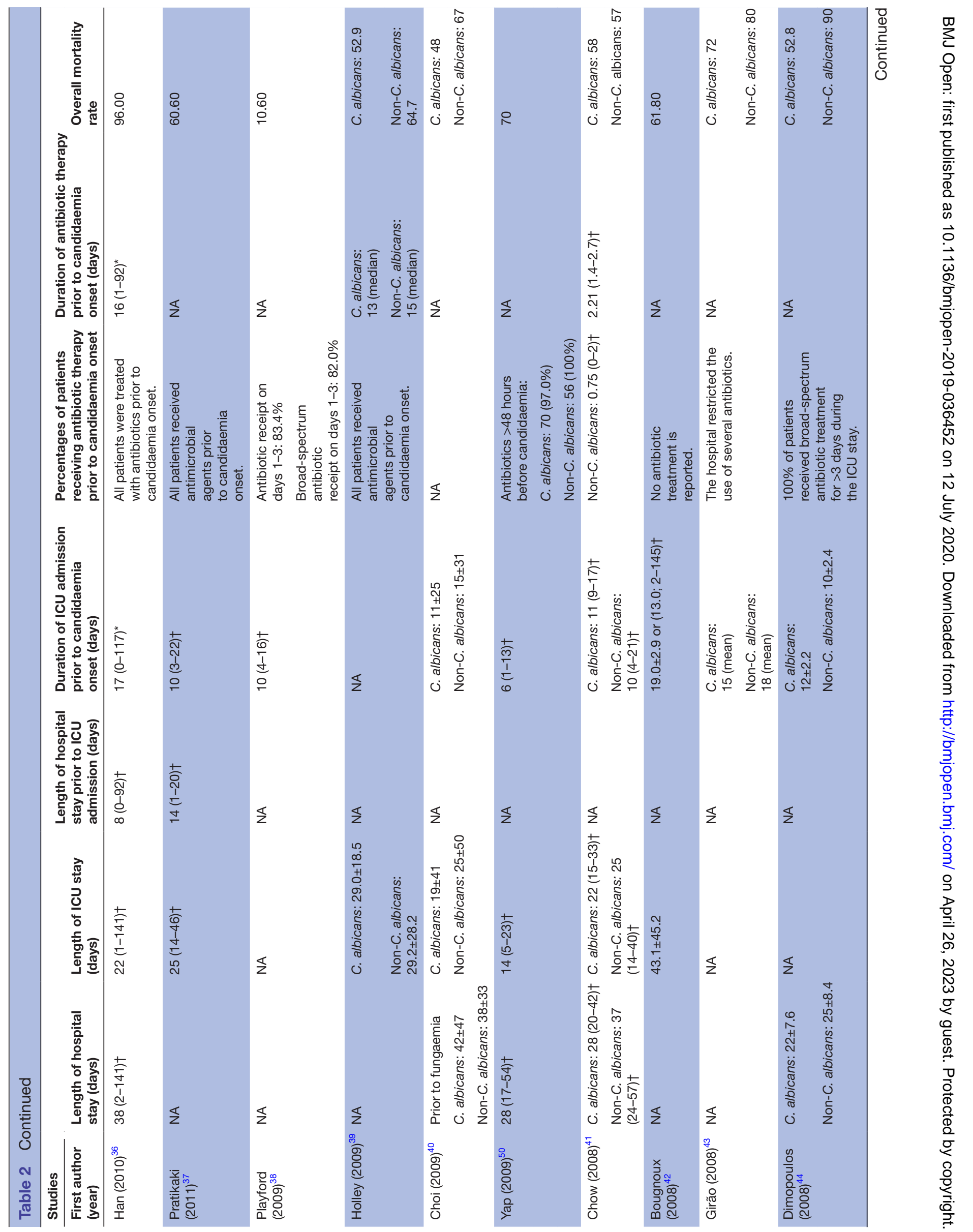




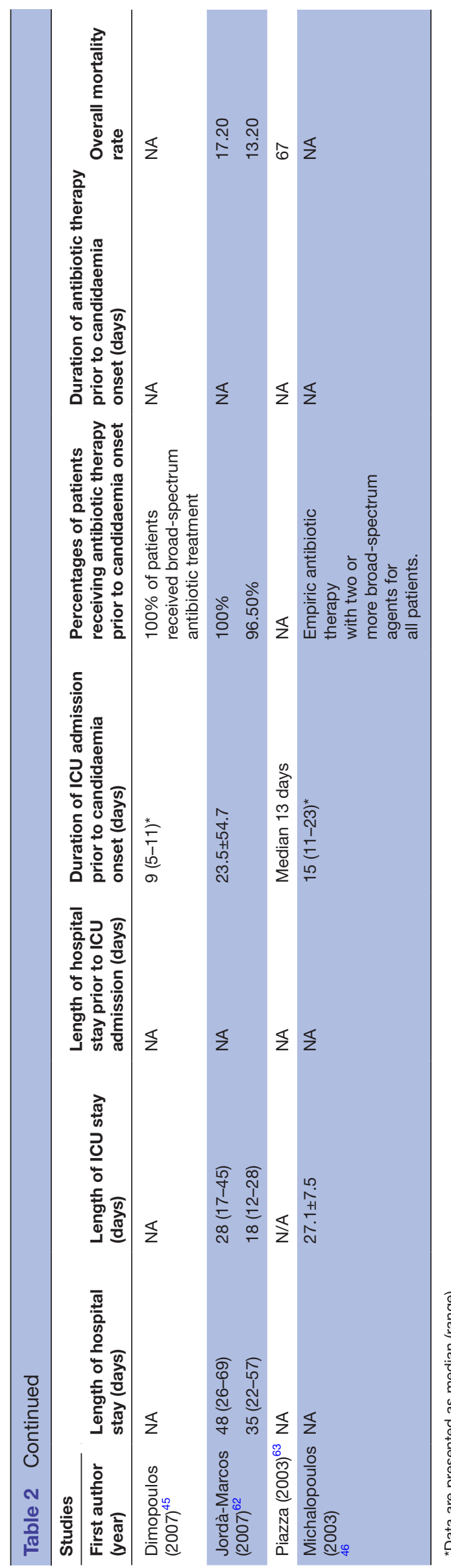

(mean=25.8 vs 26.4 days) and shorter length of hospital stay prior to ICU admission (mean $=10.8$ vs 15.2 days) than patients with IC. Furthermore, patients with C. albicans also had longer duration of ICU admission prior to candidaemia onset compared with patients with other species of $C$. albicans (mean $=11$ vs 10 days). The mean durations of ICU admission prior to candidaemia onset in hospitalised patients were 18.5 days (95\% CI 15.3 to 21.7 days) in Europe, 17.4 days (95\% CI 14.6 to 20.2 days) in Asia and 45.8 days (95\% CI 27.8 to 63.7 days) in South America. Data from Girão $e t a t^{43}$ and Gong $e t a t^{47}$ were excluded from the summarised analysis due to absence of SD for mean values and data ranges.

Broad-spectrum antibiotic use prior to candidaemia onset, length of hospital stay prior to ICU admission and overall mortality

To compare the broad-spectrum antibiotic use between patients with and without IC, we reviewed and excluded studies containing control groups with non-invasive Candida infection and/or with a clear number of broadspectrum antibiotics use. After pooling all data, the difference in the use of broad-spectrum antibiotics among patients with IC $(89.1 \%, 95 \%$ CI $82.7 \%$ to $93.4 \%)$ prior to IC onset versus those without IC $(77.4 \%, 95 \%$ CI $52.3 \%$ to $91.4 \%$ ) did not reach statistical significance. The mean duration of antibiotic therapy prior to candidaemia onset was 17.8 days (95\% CI 9.3 to 26.3), but the duration of broad-spectrum antibiotic use prior to the infection could not be determined due to insufficient data. Only five studies reported length of hospital stay prior to ICU admission and the mean was 11.7 days $(95 \%$ CI 0.4 to 23.1). The overall mortality rate increased from $49.3 \%$ to $51.0 \%$ after excluding four China-SCAN studies (table 3).

\section{Comparing the effect between $C$. albicans and non-C. albicans}

A meta-analysis was performed to compare the effect of length of hospital stay, length of ICU stay and overall mortality between patients infected with C. albicans and those infected with different strains of Candida. Three studies examined the length of hospital stay, ${ }^{40} 4144$ three studies examined the length of ICU stay, ${ }^{39-41}$ and six studies examined overall mortality ${ }^{39-41} 434447$; these were selected for the meta-analysis. According to the heterogeneity test, a random-effect model was applied for the length of hospital stay $\left(\mathrm{Q}=25.47, \mathrm{I}^{2}=92.1 \%, \mathrm{p}<0.001\right)$ and overall mortality rate $\left(\mathrm{Q}=399, \mathrm{I}^{2}=98.7 \%, \mathrm{p}<0.001\right)$, while a fixed-effect model was applied for the length of ICU stay $\left(\mathrm{Q}=1.56, \mathrm{I}^{2}=0 \%, \mathrm{p}=0.458\right)$. The pooled effect demonstrated no significant difference in length of hospital stay between patients with and without C. albicans ( $\mathrm{p}>0.05$; figure 2A); however, there was a significant difference in mean length of ICU stay (difference in means $=2.8$ days, $\mathrm{p}<0.001$; figure $2 \mathrm{~B}$ ). There was also no significant difference in overall mortality between patients with and without C. albicans ( $>0.05$; figure $2 \mathrm{C})$. 
Table 3 Summary of length of hospital stay, length of ICU stay, duration of ICU admission and hospital stay prior to candidaemia onset, and overall mortality in the overall or given subgroups $\ddagger \S$

\begin{tabular}{|c|c|c|c|c|c|}
\hline & $\begin{array}{l}\text { Length of hospital } \\
\text { stay (days) }\end{array}$ & $\begin{array}{l}\text { Length of ICU stay } \\
\text { (days) }\end{array}$ & $\begin{array}{l}\text { Duration of ICU } \\
\text { admission prior } \\
\text { to candidaemia } \\
\text { onset (days) }\end{array}$ & $\begin{array}{l}\text { Length of hospital } \\
\text { stay prior to ICU } \\
\text { admission (days) }\end{array}$ & Overall mortality \\
\hline Comparison & Mean $(95 \% \mathrm{Cl})$ & Mean $(95 \% \mathrm{Cl})$ & Mean $(95 \% \mathrm{Cl})$ & Mean $(95 \% \mathrm{Cl})$ & Rate $(95 \% \mathrm{Cl})$ \\
\hline Overall & 36.3 (25.8 to 46.7$)$ & 25.8 (23.6 to 28.1 ) & $12.9(11.7$ to 14.2$)$ & 11.7 (0.4 to 23.1$)$ & 49.3 (45.0 to 53.5 ) \\
\hline Overall optional ${ }^{\star} \dagger$ & $37.5(33.3 \text { to } 41.6)^{\star}$ & $25.9(23.5 \text { to } 28.3)^{\star}$ & $13.7(12.5$ to 15.0$) \dagger$ & - & $51.0(46.6$ to 55.4$) \dagger$ \\
\hline \multicolumn{6}{|l|}{ Subgroups } \\
\hline \multicolumn{6}{|l|}{ Type of study } \\
\hline Prospective & 41.0 (32.9 to 49.1$)$ & 27.4 (24.6 to 30.3 ) & $12.9(11.5$ to 14.4$)$ & 19.2 (17.2 to 21.3$)$ & 42.7 (37.9 to 47.4$)$ \\
\hline $\begin{array}{l}\text { Retrospective/ } \\
\text { cross-sectional }\end{array}$ & $31.9(18.2$ to 45.5$)$ & 23.9 (21.1 to 26.6$)$ & 13.7 (11.2 to 16.2$)$ & $7.4(-3.7$ to 18.4$)$ & 56.5 (48.0 to 65.0$)$ \\
\hline \multicolumn{6}{|l|}{$\begin{array}{l}\text { Presence of } \\
\text { neutropaenia }\end{array}$} \\
\hline Neutropaenia & 34.9 (19.8 to 50.1$)$ & 25.4 (19.3 to 31.5$)$ & 11.6 (9.5 to 13.8$)$ & - & 49.6 (40.8 to 58.3$)$ \\
\hline Non-neutropaenia & 22.9 (20.9 to 25.0$)$ & - & $10.0(9.3$ to 10.7$)$ & - & 41.3 (7.9 to 74.7$)$ \\
\hline \multicolumn{6}{|l|}{ Type of ICU } \\
\hline ICU & 37.7 (21.7 to 53.7$)$ & 27.3 (24.9 to 29.7 ) & 14.3 (5.7 to 6.0$)$ & 17.2 (11.9 to 22.4$)$ & 49.8 (44.3 to 55.3$)$ \\
\hline SICU & - & 21.7 (19.5 to 23.9$)$ & 17.3 (11.9 to 22.7$)$ & - & 33.1 (15.2 to 51.1$)$ \\
\hline MICU & - & 32.7 (10.3 to 55.2$)$ & 17.0 (16.2 to 17.8$)$ & - & 88.4 (72.8 to 104.1$)$ \\
\hline $\mathrm{MICU}+\mathrm{SICU}$ & 34.6 (28.2 to 41.1$)$ & 22.5 (18.4 to 26.6 ) & 10.9 (9.6 to 12.3$)$ & - & 45.7 (36.4 to 55.0$)$ \\
\hline \multicolumn{6}{|l|}{ Candida albicans } \\
\hline C. albicans & 34.2 (33.1 to 35.3) & 25.9 (22.3 to 29.5 ) & 11.0 (10.7 to 11.3$)$ & - & 52.2 (40.0 to 64.4$)$ \\
\hline Non-C. albicans & 27.0 (24.3 to 29.8 ) & 25.0 (18.0 to 31.9$)$ & - & - & - \\
\hline \multicolumn{6}{|l|}{$\begin{array}{l}\text { Presence of IC/ } \\
\text { candidaemia }\end{array}$} \\
\hline Candidaemia & 36.3 (32.9 to 39.8 ) & 25.8 (23.2 to 28.3 ) & 13.2 (12.0 to 14.5$)$ & 10.8 (-2.0 to 23.6$)$ & 51.4 (47.1 to 55.8$)$ \\
\hline IC & $33.9(-3.7$ to 71.4$)$ & 26.4 (20.7 to 32.1) & 11.5 (7.7 to 15.3$)$ & - & 38.9 (27.8 to 50.1$)$ \\
\hline \multicolumn{6}{|l|}{ Region(s) } \\
\hline Asia & 36.9 (23.0 to 50.8$)$ & 25.0 (20.9 to 29.0$)$ & 17.4 (14.6 to 20.2$)$ & 19.3 (17.2 to 21.4$)$ & 51.2 (44.7 to 57.7$)$ \\
\hline $\begin{array}{l}\text { Europe/USA } \\
\text { Australia }\end{array}$ & 33.3 (20.8 to 45.8 ) & 27.7 (23.3 to 32.1$)$ & 18.5 (15.3 to 21.7$)$ & $9.6(-1.2$ to 20.4$)$ & 48.6 (42.4 to 54.7 ) \\
\hline South America & - & - & 45.8 (27.8 to 63.7$)$ | & - & 54.4 (38.0 to 70.7 ) \\
\hline
\end{tabular}

Certain subgroups have only one study $(\mathrm{df}=0)$.

Dash indicates no available data.

${ }^{*}$ Excluded Yang et $a l^{26}$ (2017), Gong et al (2016), ${ }^{47}$ Liao et $a l^{14}$ (2015) and Guo et al ${ }^{49}$ (2013).

†Excluded Yang et al ${ }^{26}$ (2017) Gong et al ${ }^{47}$ (2016), Liao et al (2015) $)^{14}$ and Hu et al ${ }^{48}$ (2014).

†The range of $95 \% \mathrm{Cl}$ is related to the accuracy of the estimation. The narrower the range, the higher the accuracy of the estimation. If both the upper and lower limits are positive, the clinical outcome estimate for the group of participants is positive; if the lower limit is negative and the upper limit is positive, it indicates that the clinical outcome estimate for the type of participants is not significantly greater than 0. §Meta-regression is used to assess the relationship between study-level covariates and effect size when obvious heterogeneity exists in subgroups.

TMeta-regression analysis illustrated South American patients had significantly longer duration of ICU admission prior to candidaemia onset than their counterparts in Asia, Australia, Europe and North America (using Asia as the reference group, for South America: $\beta=25.83$, $\mathrm{p}=0.0308, \mathrm{R}^{2}=0.097$ ). Other meta-regression analyses in subgroups in this table did not reach statistical significance.

IC, invasive candidiasis; ICU, intensive care unit; MICU, medical intensive care unit; SICU, surgical intensive care unit.

\section{Quality assessment}

The results of the quality assessment are shown in table 4 . Regarding the results of ROBINS-I, nine studies had serious bias due to confounding because no baseline confounding or appropriate analysis methods were used to adjust for important baseline confounding. Five studies had serious bias in the selection of participants due to unclear inclusion and exclusion criteria. Most 
A. Length of hospital stay (days)

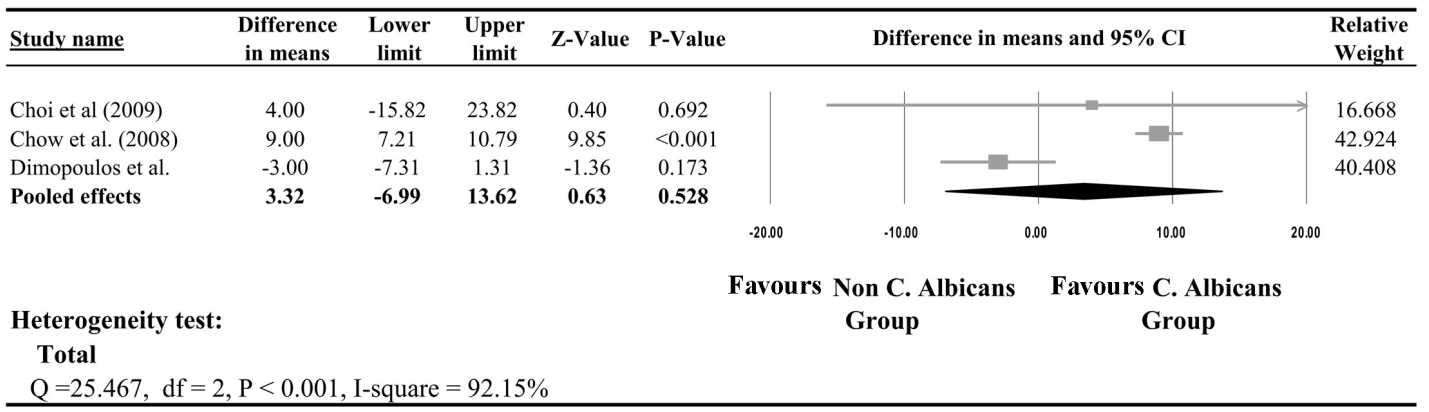

B. ICU length of stay (days)

\begin{tabular}{|c|c|c|c|c|c|c|c|}
\hline Study name & $\begin{array}{c}\text { Difference in } \\
\text { means }\end{array}$ & $\begin{array}{c}\text { Lower } \\
\text { limit }\end{array}$ & $\begin{array}{c}\text { Upper } \\
\text { limit }\end{array}$ & Z-Value & P-Value & Difference in means and $95 \% \mathrm{CI}$ & $\begin{array}{l}\text { Relative } \\
\text { Weight }\end{array}$ \\
\hline Holley et al. (200S & -0.20 & -6.89 & 6.49 & -0.06 & 0.953 & 1 & 4.372 \\
\hline Choi et al. (2009) & -6.00 & -26.40 & 14.40 & -0.58 & 0.564 & & 0.471 \\
\hline Chow et al. (2008) & 3.00 & 1.56 & 4.44 & 4.10 & $<0.001$ & & 95.157 \\
\hline Pooled effects & 2.82 & 1.42 & 4.22 & 3.94 & $<0.001$ & & \\
\hline
\end{tabular}

Heterogeneity test:

Favours Non C. Albicans Favours C. Albicans

Total

Group Group

$\mathrm{Q}=1.560, \mathrm{df}=2, \mathrm{P}=0.458, \mathrm{I}$-square $=0 \%$

\section{Overall mortality}

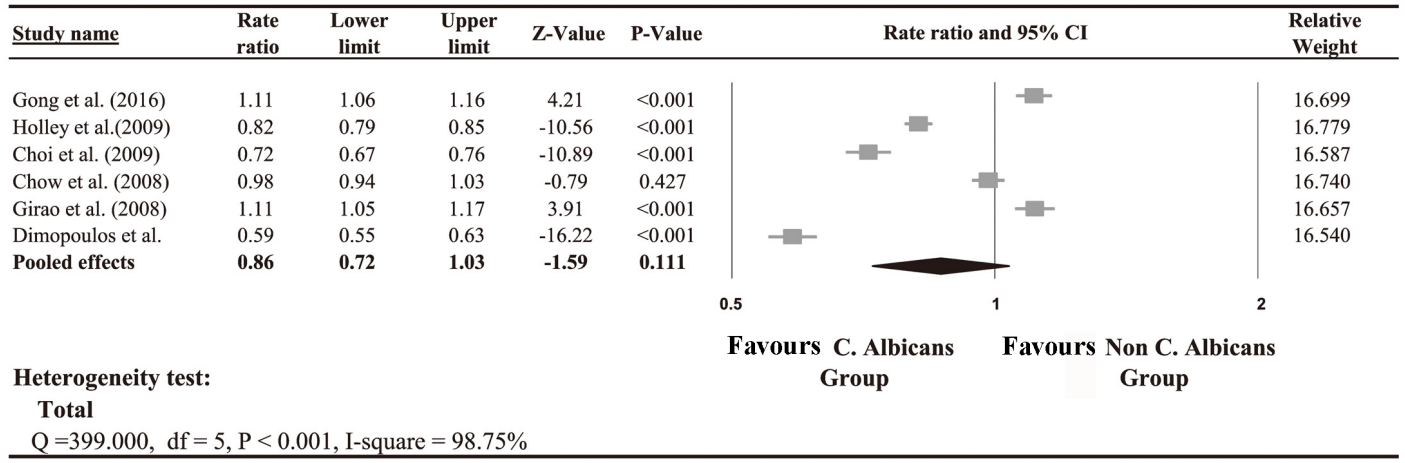

Figure 2 Meta-Analysis of Candida albicans vs non-Candida albicans for (A) length of hospital stay, (B) intensive care unit (ICU) length of stay and $(\mathrm{C})$ overall mortality.

of the studies had low or moderate bias in classification of interventions. No study provided information on the systematic difference between experimental intervention and comparator groups due to a lack of comparison of two intervention groups. All studies had low or moderate bias in missing data, in measurement of outcomes and in selection of the reported results. Overall, 28 studies had moderate risk of bias, 13 had serious risk of bias, and 1 had unclear information regarding the risk of bias.

\section{Meta-regression of clinical outcomes}

A meta-regression analysis demonstrated that South American patients had significantly longer mean duration of ICU admission prior to candidaemia onset than patients in Asia, Australia, Europe and North America (using Asia as the reference group, South America had $\beta=25.83, \mathrm{p}=0.0308$, $\left.\mathrm{R}^{2}=0.097\right)$. Other subgroup meta-regression analyses did not reach statistical significance (table 3). The level of risk of bias (moderate/serious or no information) was also included in the meta-regression analyses and the coefficient was not found to achieve statistical significance.

\section{Publication bias}

Egger's test showed potential publication bias for length of hospital stay (one-tailed $\mathrm{p}<0.001$ ) and duration of ICU admission prior to candidaemia onset (one-tailed $\mathrm{p}=0.004)$; there was no significant publication bias for length of ICU stay (one-tailed $\mathrm{p}=0.37$ ) and overall mortality (one-tailed $\mathrm{p}=0.38$ ). The classic fail-safe $\mathrm{N}$ tests indicated that the number of missing studies which would be needed to make the $p$ values of the summary effect become insignificant was 65685 for length of stay, 2304 for length of ICU stay, 89242 for duration of ICU admission prior to candidaemia onset and 34263 for 


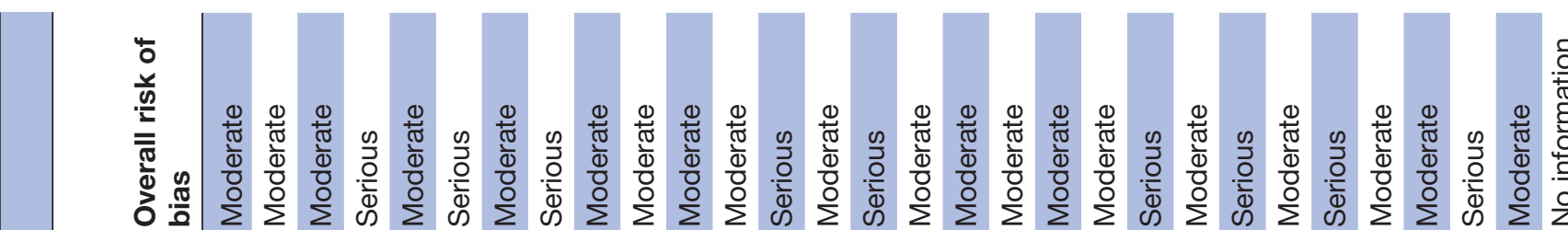

휴

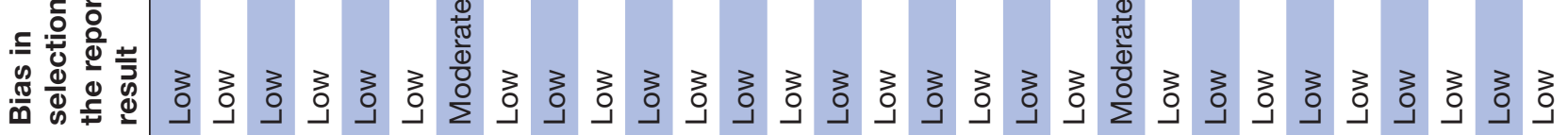

¿

农

$\stackrel{\oplus}{\text { है }}$

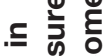

亩

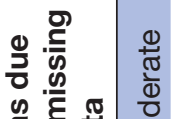

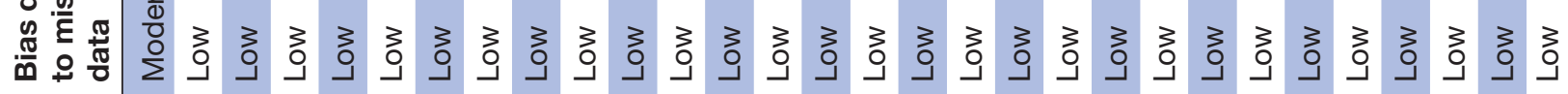

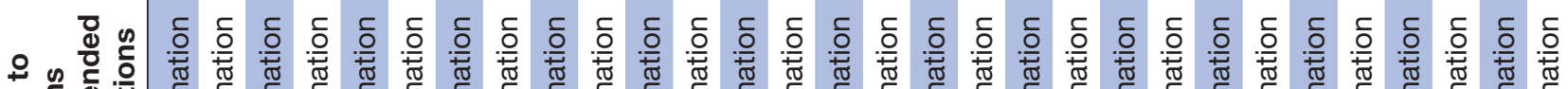

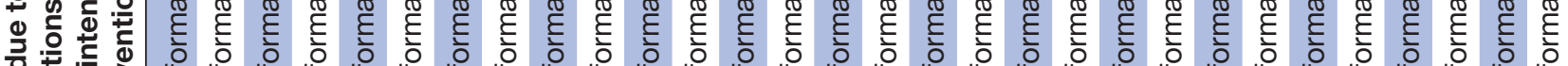

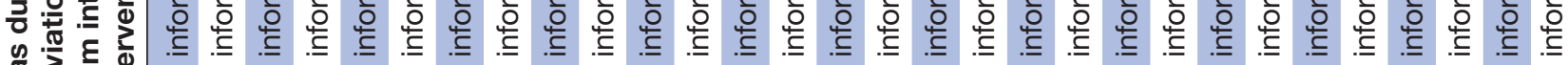

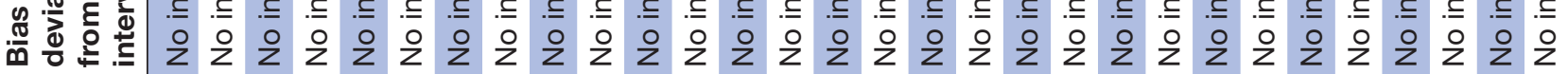

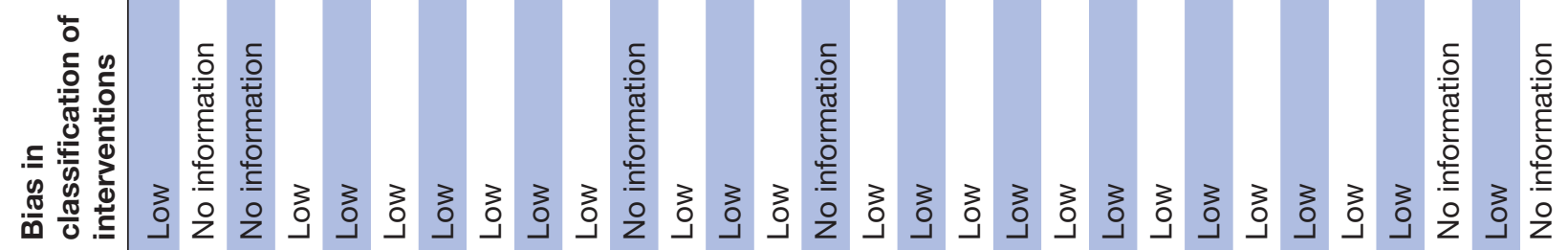

它

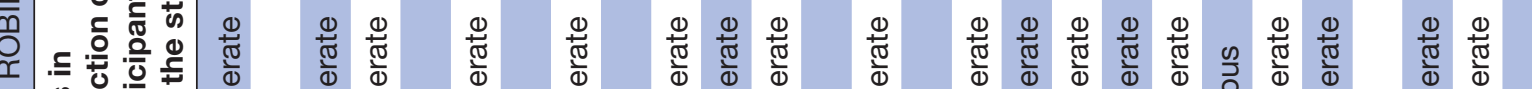

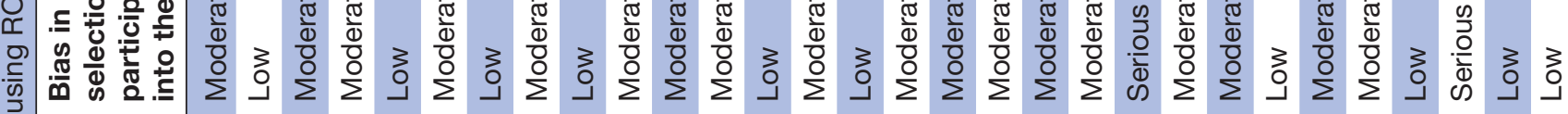

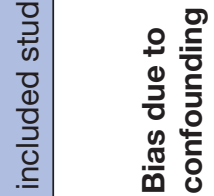

$\stackrel{\frac{}{\circ}}{\frac{0}{\pi}}$

पँ

蒙

$\frac{E}{\infty}$
0
0
0
0

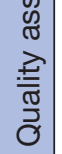

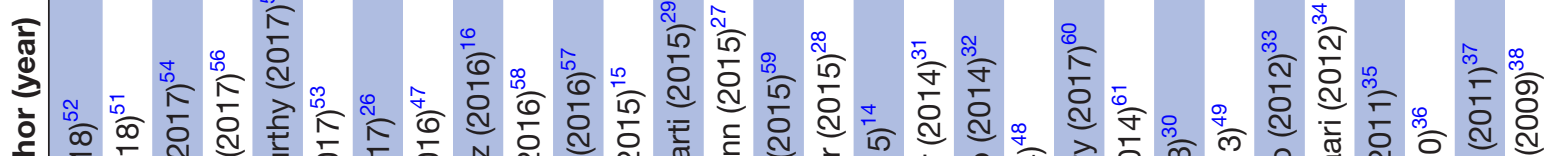

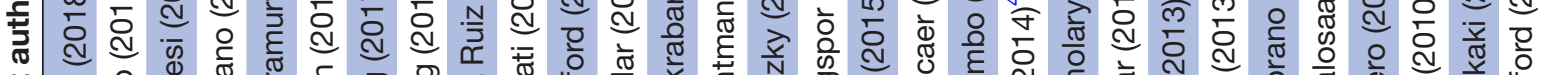

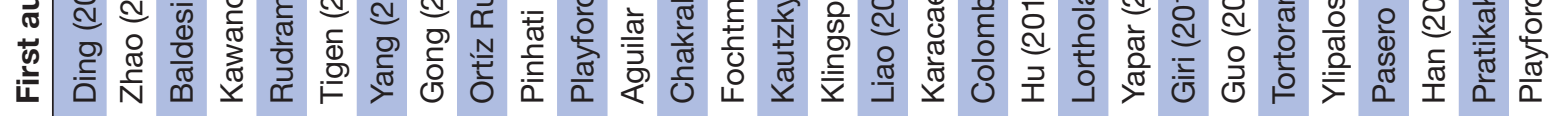




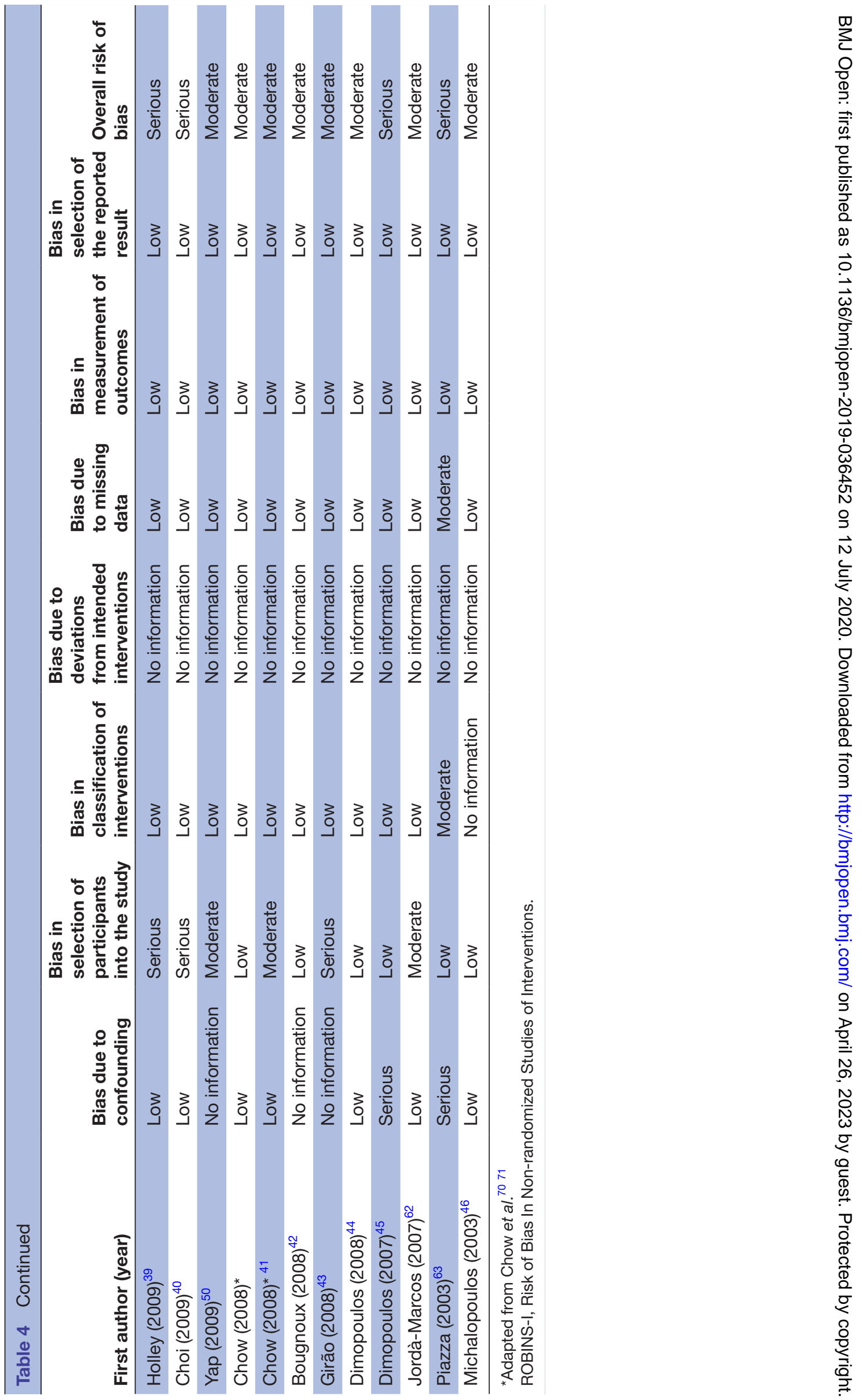


overall mortality. These results indicated that the significance of the observed effects of the meta-analyses would not be influenced by the inclusion of additional studies (figure 3A-C).

\section{DISCUSSION}

The current meta-analysis demonstrated that the pooled mean of duration of ICU admission prior to candidaemia varied from approximately 17 days in Asia to 19 days in Europe and 46 days in South America. Most of the patients with IC had received broad-spectrum antibiotics $(89 \%)$, and the mean duration of antibiotic therapy prior to candidaemia onset was nearly 18 days. The pooled mean mortality rate was approximately $49 \%$. There was no significant difference in the length of hospital stay or overall mortality between patients with and without $C$. albicans, but the mean length of ICU stay was longer for patients with C. albicans compared with patients without C. albicans.

As for the study design, eight were case-control or cross-sectional studies, and the remaining 33 were retrospective or prospective cohort studies (table 1). Eleven studies were designed to compare patients with and without candidaemia. Five studies compared patients with infection of $C$. albicans versus those infected with another Candida strain, and only one study compared ICU-acquired candidaemia versus non-ICU acquired candidaemia. ${ }^{34}$ Eight studies were performed in Chinese hospitals (table 1). Two studies evaluated patients with C. albicans versus non-C. albicans infection. One study compared patients with CRCBSI versus non-CRCBSI, and another study compared patients with a fluconazoleresistant versus fluconazole-sensitive infection.

Fewer than half of the studies $(n=18)$ were conducted in general or multidisciplinary ICUs, with the rest in SICUs, in the cardiosurgical/cardiothoracic $\mathrm{ICUs}^{46}$ or in MICUs. ${ }^{36}$ This suggests that IC is a common problem in critically ill patients regardless of ICU type. The mean length of hospital stay ranged from 4 (early-onset group) to 54 days, and the mean length of ICU stay ranged from 7 days to 60 days (table 2). In nine studies, the median length of ICU stay was $\leq 10$ days prior to onset of IC, and the overall mortality in ICU patients with candidaemia in these studies ranged from $10.6 \%$ to $65.8 \%$. In studies with a median length of ICU stay $>10$ days prior to onset of IC, the overall mortality ranged from $13.6 \%$ to $96.0 \%$.

The durations of ICU stay varied widely prior to candidaemia onset, which indicated the time and circumstances involved in encountering ICU-acquired risk factors might differ among critically ill patients. As we have mentioned previously, one major cause of severe candidiasis is the endogenous colonisation of Candida species, which requires a period of 7-10 days for the development of IC after exposure to the risk factors. ${ }^{20} \mathrm{In}$ addition, the median time for obtaining positive blood cultures was 2-3 days (possibly up to $\geq 7$ days). ${ }^{2}$ Thus, for a patient with the confirmed diagnosis of candidaemia at 8 days after ICU admission, the endogenous colonisation of Candida species might have actually occurred on or before the first day of ICU admission. Similarly, for a patient with the confirmed diagnosis of candidaemia at 12-13 days after ICU admission, the endogenous colonisation of Candida species might have occurred 3-5 days after ICU admission.

One main risk factor for candidaemia was systemic antibiotic use. ${ }^{16}$ In a previous study of paediatric ICUs, it was reported that treatment with vancomycin or antianaerobic antibiotics for $>3$ days was independently associated with the development of candidaemia, ${ }^{2}$ but only in an unadjusted analysis. ${ }^{16}$ A study in Hong Kong found that candidaemia occurred in patients within 6 days of ICU admission, and more than $97.0 \%$ of patients infected with fungi of Candida species had received $>48$ hours of antibiotic treatment. ${ }^{64}$ Overuse and prolonged use of broad-spectrum antibiotics have been closely associated with candidaemia in China and India ${ }^{65}{ }^{66}$ so it is reasonable to suspect a link between overuse of broad-spectrum antibiotics and early-onset of candidaemia after ICU admission. Regardless of geographical differences, most patients with IC received broadspectrum antibiotic treatment prior to candidaemia onset in the ICU. However, due to a lack of sufficient data, potential correlation between prolonged exposure to broadspectrum antibiotics and the time of candidaemia onset after ICU admission could not be assessed. Further explanations on the longer duration of ICU admission prior to candidaemia onset in South America than in Asia/Europe/ USA/Australia also could not be determined in this systematic review.

The results of this study showed no significant difference in the length of hospital stay prior to the development of IC and in the overall mortality between patients with and without invasive infection of $C$. albicans. This may be due to the fact that clinical presentation and the treatment of patients with candidaemia caused by C. albicans and non-C. albicans were indistinguishable ${ }^{67}$ Although it was found that the mortality rates in patients with C. albicans and non-C. albicans were similar, the susceptibilities of these strains to antifungal agents were different. ${ }^{2168} 69$

This systematic review had several limitations. Because this systematic review lacks a prespecified protocol and preliminary registration, biased post-hoc decisions in the reviewing process may occur. In addition, a number of trials reported outcomes using median (range) and/or median (IQR), and in order to combine these results the sample mean and SD for those trials were estimated using a method proposed by Wan $e t a l,{ }^{24}$ based on the assumption that data were normally distributed. Across the meta-analysis, however, medians and quartiles were often reported when data did not follow a normal distribution, ${ }^{23}$ which may have confounded the results. The results of the quality assessment also indicated that potential biases from confounders may be present. High heterogeneity existed in both overall and subgroup analyses, suggesting complexity of the risk factors causing IC and candidaemia (online supplementary table S2). 
a

Open access

A

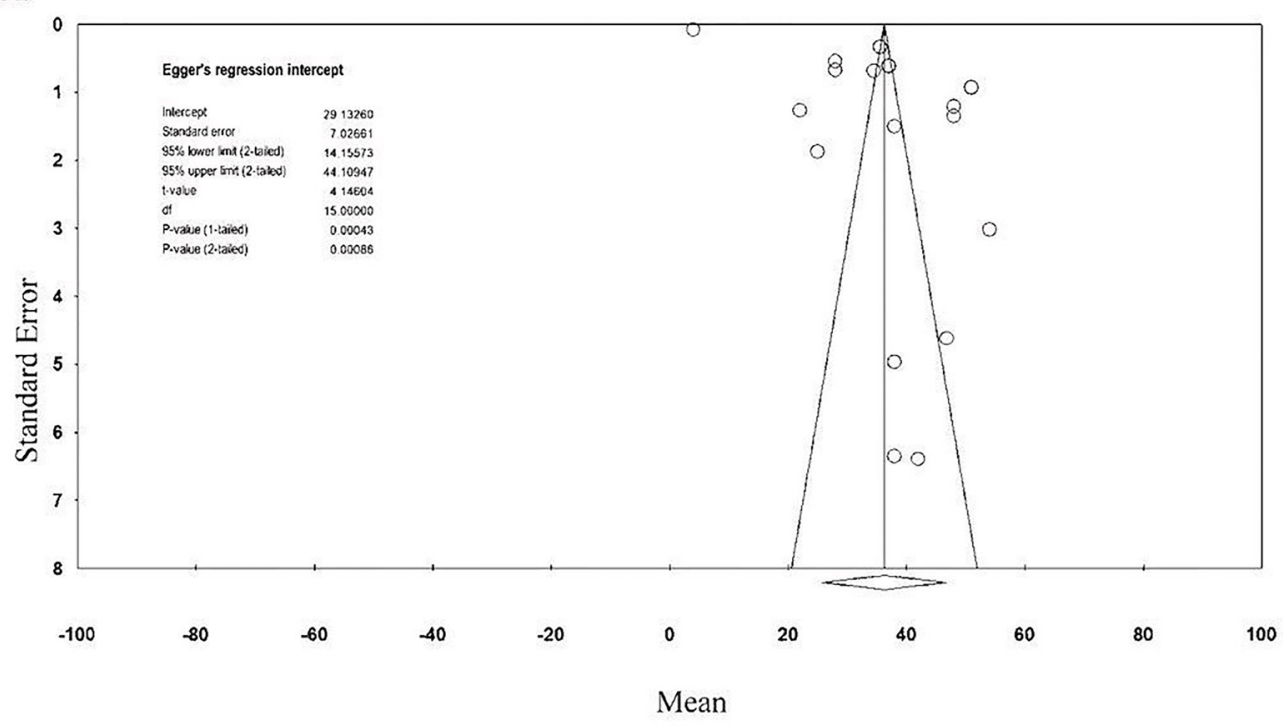

$\mathrm{B}$

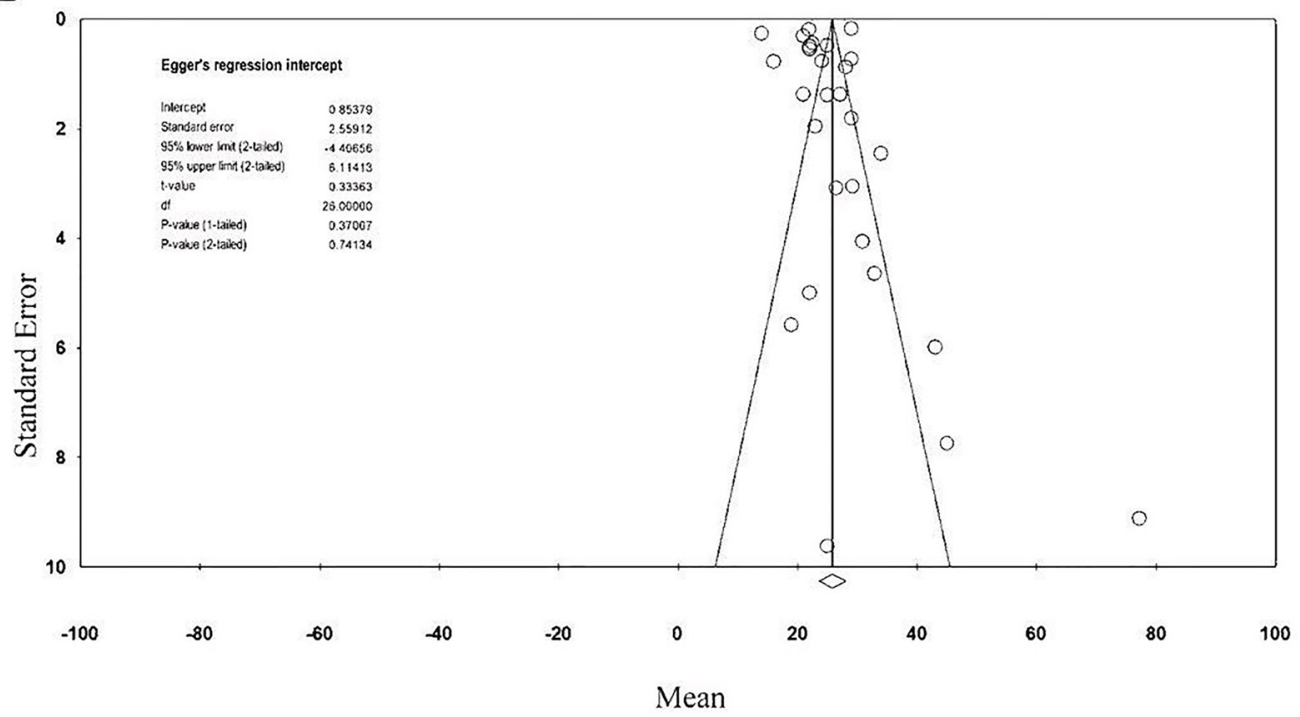

C

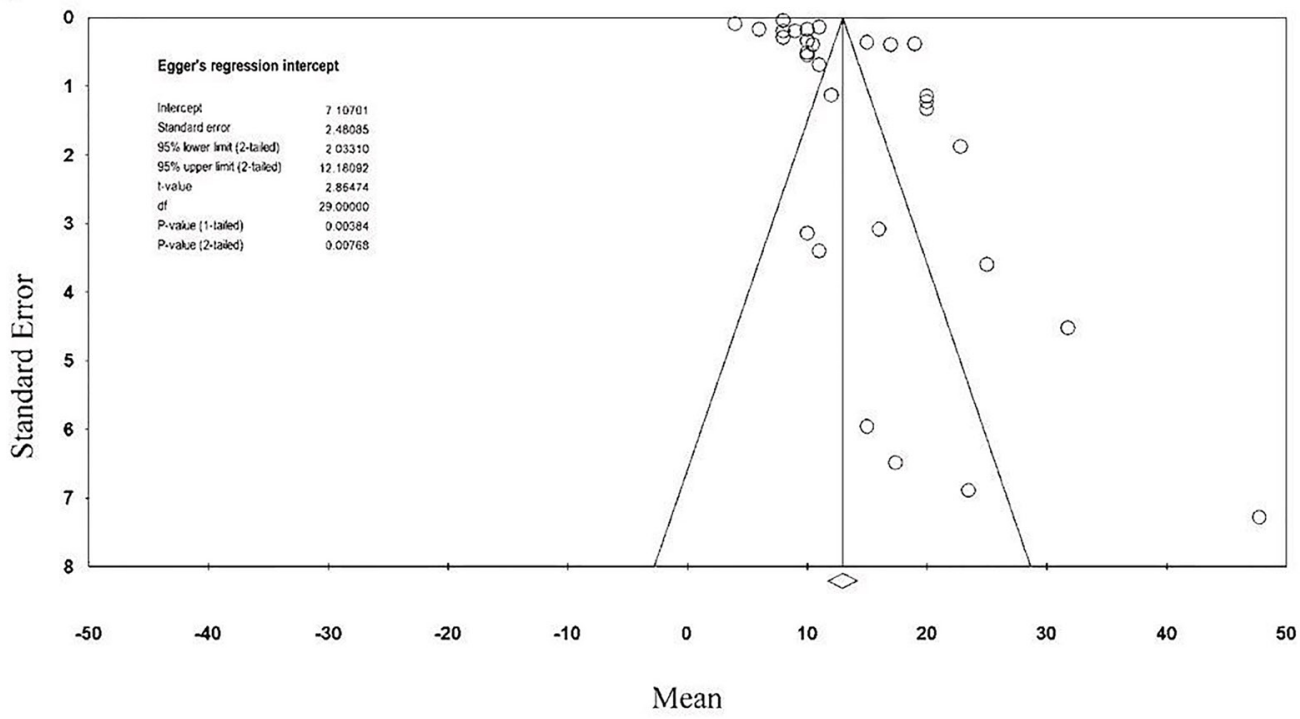

Figure 3 Funnel plot for (A) length of hospital stay, (B) ICU length of stay and (C) duration of ICU admission prior to candidaemia onset. ICU, intensive care unit.

Chang Z, et al. BMJ Open 2020;10:e036452. doi:10.1136/bmjopen-2019-036452

21 
Although different designs, regional differences and risks of bias may contribute to the heterogeneity between groups, there may be other potential factors that require further study. Factors such as comorbidities, severity of illness and invasive procedures (eg, haemodialysis, invasive mechanical ventilation, total parenteral nutrition, surgery and immunosuppression) were not taken into account in this analysis. Publication bias may have existed in some analysed outcomes as well.

This meta-analysis finds that patients who had longer length of ICU stay were more likely to develop candidaemia. Therefore, early detection and therapeutic intervention should be considered in the ICU to reduce potential risk of fungal infection and its complications, which will help conserve valuable medical resources and ultimately save more lives.

Acknowledgements Medical writing and editorial assistance were provided by Elizabeth Goodwin and Professor Jerry Tseng of MedCom Asia, China.

Contributors ZZ, RZ, ZL, XM: guarantor of integrity of the entire study, study concepts, study design, definition of intellectual content, manuscript editing, manuscript review. The authors initiated the concept for this systematic review and are responsible for the content of the manuscript.

Funding The authors have not declared a specific grant for this research from any funding agency in the public, commercial or not-for-profit sectors. Medical writing and editorial assistance was funded by MSD China.

Competing interests None declared.

Patient consent for publication Not required.

Provenance and peer review Not commissioned; externally peer reviewed.

Data availability statement No data are available. All data relevant to the study are included in the article or uploaded as supplementary information.

Open access This is an open access article distributed in accordance with the Creative Commons Attribution Non Commercial (CC BY-NC 4.0) license, which permits others to distribute, remix, adapt, build upon this work non-commercially, and license their derivative works on different terms, provided the original work is properly cited, appropriate credit is given, any changes made indicated, and the use is non-commercial. See: http://creativecommons.org/licenses/by-nc/4.0/.

ORCID iD

Xiaochun Ma http://orcid.org/0000-0002-9430-6187

\section{REFERENCES}

1 Calandra T, Roberts JA, Antonelli M, et al. Diagnosis and management of invasive candidiasis in the ICU: an updated approach to an old enemy. Crit Care 2016;20.

2 Pappas PG, Kauffman CA, Andes DR, et al. Executive summary: clinical practice guideline for the management of candidiasis: 2016 update by the infectious diseases Society of America. Clin Infect Dis 2016;62:409-17.

3 Bassetti M, Peghin M, Timsit J-F. The current treatment landscape: candidiasis. J Antimicrob Chemother 2016;71:ii13-22.

4 Yapar N. Epidemiology and risk factors for invasive candidiasis. Ther Clin Risk Manag 2014;10:95-105.

5 Strollo S, Lionakis MS, Adjemian J, et al. Epidemiology of Hospitalizations Associated with Invasive Candidiasis, United States, 2002-2012 ${ }^{1}$. Emerg Infect Dis 2016;23:7-13.

6 León C, Ostrosky-Zeichner L, Schuster M. What's new in the clinical and diagnostic management of invasive candidiasis in critically ill patients. Intensive Care Med 2014;40:808-19.

7 Yang S-P, Chen Y-Y, Hsu H-S, et al. A risk factor analysis of healthcare-associated fungal infections in an intensive care unit: a retrospective cohort study. BMC Infect Dis 2013;13.

8 Montagna MT, Lovero G, Borghi E, et al. Candidemia in intensive care unit: a nationwide prospective observational survey (GISIA-3 study) and review of the European literature from 2000 through 2013. Eur Rev Med Pharmacol Sci 2014;18:661-74.
9 Bassetti M, Garnacho-Montero J, Calandra T, et al. Intensive care medicine research agenda on invasive fungal infection in critically ill patients. Intensive Care Med 2017;43:1225-38.

10 Clancy CJ, Nguyen $\mathrm{MH}$. The end of an era in defining the optimal treatment of invasive candidiasis. Clin Infect Dis 2012;54:1123-5.

11 Kullberg BJ, Arendrup MC. Invasive candidiasis. N Engl J Med 2016;374:794-5.

12 Paphitou NI, Ostrosky-Zeichner L, Rex JH. Rules for identifying patients at increased risk for candidal infections in the surgical intensive care unit: approach to developing practical criteria for systematic use in antifungal prophylaxis trials. Med Mycol 2005;43:235-43.

13 Ostrosky-Zeichner L, Sable C, Sobel J, et al. Multicenter retrospective development and validation of a clinical prediction rule for nosocomial invasive candidiasis in the intensive care setting. Eur $J$ Clin Microbiol Infect Dis 2007;26:271-6.

14 Liao X, Qiu H, Li R, et al. Risk factors for fluconazole-resistant invasive candidiasis in intensive care unit patients: an analysis from the China survey of candidiasis study. J Crit Care 2015;30:862. e1-862.e5.

15 Aguilar G, Delgado C, Corrales I, et al. Epidemiology of invasive candidiasis in a surgical intensive care unit: an observational study. BMC Res Notes 2015;8:491.

16 Ortíz Ruiz G, Osorio J, Valderrama S, et al. Risk factors for candidemia in non-neutropenic critical patients in Colombia. Med Intensiva 2016;40:139-44.

17 Ostrosky-Zeichner L. Clinical prediction rules for invasive candidiasis in the ICU: ready for prime time? Crit Care 2011;15:189.

18 León C, Ruiz-Santana S, Saavedra P, et al. Contribution of Candida biomarkers and DNA detection for the diagnosis of invasive candidiasis in ICU patients with severe abdominal conditions. Crit Care 2016;20.

19 Martín-Mazuelos E, Loza A, Castro C, et al. $\beta$-D-Glucan and Candida albicans germ tube antibody in ICU patients with invasive candidiasis. Intensive Care Med 2015;41:1424-32.

20 Eggimann P, Que Y-A, Revelly J-P, et al. Preventing invasive Candida infections. where could we do better? J Hosp Infect 2015;89:302-8.

21 Sterne JA, Hernán MA, Reeves BC, et al. ROBINS-I: a tool for assessing risk of bias in non-randomised studies of interventions. BMJ 2016;355:i4919.

22 Sterne JAC, Higgins JPT, et al, The development group for ROBINS-I. Risk Of bias. In: Non-randomized studies of interventions (ROBINS-I)detailed guidance, 2016. http://www. riskofbias.info

23 Zeng X, Zhang Y, Kwong JSW, et al. The methodological quality assessment tools for preclinical and clinical studies, systematic review and meta-analysis, and clinical practice guideline: a systematic review. J Evid Based Med 2015;8:2-10.

24 Wan X, Wang W, Liu J, et al. Estimating the sample mean and standard deviation from the sample size, median, range and/or interquartile range. BMC Med Res Methodol 2014;14:135.

25 Sterne JAC, Sutton AJ, loannidis JPA, et al. Recommendations for examining and interpreting funnel plot asymmetry in meta-analyses of randomised controlled trials. BMJ 2011;343:d4002.

26 Yang Y, Guo F, Kang Y, et al. Epidemiology, clinical characteristics, and risk factors for mortality of early- and late-onset invasive candidiasis in intensive care units in China. Medicine 2017;96:e7830.

27 Fochtmann A, Forstner C, Hagmann M, et al. Predisposing factors for candidemia in patients with major burns. Burns 2015;41:326-32.

28 Klingspor L, Tortorano AM, Peman J, et al. Invasive Candida infections in surgical patients in intensive care units: a prospective, multicentre survey initiated by the European Confederation of medical mycology (ECMM) (2006-2008). Clinical Microbiology and Infection 2015;21:87.e1-87.e10.

29 Chakrabarti A, Sood P, Rudramurthy SM, et al. Incidence, characteristics and outcome of ICU-acquired candidemia in India. Intensive Care Med 2015;41:285-95.

30 Giri S, Kindo AJ, Kalyani J. Candidemia in intensive care unit patients: a one year study from a tertiary care center in South India. J Postgrad Med 2013;59:190-5.

31 Karacaer Z, Oncul O, Turhan V, et al. A surveillance of nosocomial Candida infections: epidemiology and influences on mortalty in intensive care units. Pan Afr Med J 2014;19:398.

32 Colombo AL, Guimarães T, Sukienik T, et al. Prognostic factors and historical trends in the epidemiology of candidemia in critically ill patients: an analysis of five multicenter studies sequentially conducted over a 9-year period. Intensive Care Med 2014;40:1489-98.

33 Tortorano AM, Dho G, Prigitano A, et al. Invasive fungal infections in the intensive care unit: a multicentre, prospective, observationa study in Italy (2006-2008). Mycoses 2012;55:73-9. 
34 Ylipalosaari P, Ala-Kokko TI, Karhu J, et al. Comparison of the epidemiology, risk factors, outcome and degree of organ failures of patients with candidemia acquired before or during ICU treatment. Crit Care 2012;16:R62.

35 Pasero D, De Rosa FG, Rana NK, et al. Candidemia after cardiac surgery in the intensive care unit: an observational study. Interact Cardiovasc Thorac Surg 2011;12:374-8.

36 Han S-S, Yim J-J, Yoo C-G, et al. Clinical characteristics and risk factors for nosocomial candidemia in medical intensive care units: experience in a single hospital in Korea for 6.6 years. $J$ Korean Med Sci 2010;25:671-6.

37 Pratikaki M, Platsouka E, Sotiropoulou C, et al. Epidemiology, risk factors for and outcome of candidaemia among non-neutropenic patients in a Greek intensive care unit. Mycoses 2011;54:154-61.

38 Playford EG, Lipman J, Kabir M, et al. Assessment of clinical risk predictive rules for invasive candidiasis in a prospective multicentre cohort of ICU patients. Intensive Care Med 2009;35:2141-5

39 Holley A, Dulhunty J, Blot S, et al. Temporal trends, risk factors and outcomes in albicans and non-albicans candidaemia: an international epidemiological study in four multidisciplinary intensive care units. Int $J$ Antimicrob Agents 2009;33:554.e1-554.e7.

40 Choi HK, Jeong SJ, Lee HS, et al. Blood stream infections by Candida glabrata and Candida krusei: a single-center experience. Korean J Intern Med 2009;24:263-9.

41 Chow JK, Golan Y, Ruthazer R, et al. Risk factors for albicans and non-albicans candidemia in the intensive care unit. Crit Care Med 2008;36:1993-8.

42 Bougnoux M-E, Kac G, Aegerter P, et al. Candidemia and candiduria in critically ill patients admitted to intensive care units in France: incidence, molecular diversity, management and outcome. Intensive Care Med 2008;34:292-9.

43 Girão E, Levin AS, Basso M, et al. Seven-Year trend analysis of nosocomial candidemia and antifungal (fluconazole and caspofungin) use in intensive care units at a Brazilian university hospital. Med Mycol 2008;46:581-8.

44 Dimopoulos G, Ntziora F, Rachiotis G, et al. Candida albicans versus non-albicans intensive care unit-acquired bloodstream infections: differences in risk factors and outcome. Anesth Analg 2008;106:523-9.

45 Dimopoulos G, Karabinis A, Samonis G, et al. Candidemia in immunocompromised and immunocompetent critically ill patients: a prospective comparative study. Eur J ClinMicrobiol infect. Dis 2007;26:377-84.

46 Michalopoulos AS, Geroulanos S, Mentzelopoulos SD. Determinants of candidemia and candidemia-related death in cardiothoracic ICU patients. Chest 2003;124:2244-55.

47 Gong X, Luan T, Wu X, et al. Invasive candidiasis in intensive care units in China: risk factors and prognoses of Candida albicans and non-albicans Candida infections. Am J Infect Control 2016;44:e59-63.

$48 \mathrm{Hu}$ B, Du Z, Kang Y, et al. Catheter-Related Candida bloodstream infection in intensive care unit patients: a subgroup analysis of the China-SCAN study. BMC Infect Dis 2014;14:594.

49 Guo F, Yang Y, Kang Y, et al. Invasive candidiasis in intensive care units in China: a multicentre prospective observational study. $J$ Antimicrob Chemother 2013;68:1660-8.

50 Yap HY, Kwok KM, Gomersall CD, et al. Epidemiology and outcome of Candida bloodstream infection in an intensive care unit in Hong Kong. Hong Kong Med J 2009;15:255-61.

51 Zhao H, Wong C, Wu P, et al. An analysis of mortality and clinical characteristics of ICU-acquired candidemia patients. Chin Crit Care Med 2018;30:929-32.
52 Ding R, Ji Y, Liu B, et al. Risk factors for mortality in cases of intensive care unit-acquired candidemia: a 5.5-year, single-center, retrospective study. Int J Clin Exp Med 2018;11:9950-7.

53 Tigen ET, Bilgen H, Gurun HP, et al. Risk factors, characteristics, and outcomes of candidemia in an adult intensive care unit in turkey. Am $J$ Infec Control 2017;45:e61-3.

54 Baldesi O, Bailly S, Ruckly S, et al. ICU-acquired candidaemia in France: Epidemiology and temporal trends, 2004-2013 - A study from the REA-RAISIN network. J Infect 2017;75:59-67.

55 Rudramurthy SM, Chakrabarti A, Paul RA, et al. Candida auris candidaemia in Indian ICUs: analysis of risk factors. J Antimicrob Chemother 2017;72:1794-801.

56 Kawano Y, Togawa A, Nakamura Y, et al. Prognostic factors for candidaemia in intensive care unit patients: a retrospective analysis. Singapore Med J 2017;58:196-200.

57 Playford EG, Lipman J, Jones M, et al. Problematic Dichotomization of Risk for Intensive Care Unit (ICU)-Acquired Invasive Candidiasis: Results Using a Risk-Predictive Model to Categorize 3 Levels of Risk From a Multicenter Prospective Cohort of Australian ICU Patients. Clin Infect Dis 2016;63:1463-9.

58 Pinhati HMS, Casulari LA, Souza ACR, et al. Outbreak of candidemia caused by fluconazole resistant Candida parapsilosis strains in an intensive care unit. BMC Infect Dis 2016:16:1-6.

59 Kautzky S, Staudinger T, Presterl E. Invasive Candida infections in patients of a medical intensive care unit. Wien Klin Wochenschr 2015;127:132-42.

60 Lortholary O, Renaudat C, Sitbon K, et al. The risk and clinical outcome of candidemia depending on underlying malignancy. Intensive Care Med 2017;43:652-62.

61 Yapar N, Akan M, Avkan-Oguz V, et al. Risk factors, incidence and outcome of candidemia in a Turkish intensive-care unit: a five-year retrospective cohort study. Anaesth Pain Intensive Care 2014;18:265-71.

62 Jordà-Marcos R, Alvarez-Lerma F, Jurado M, et al. Risk factors for candidaemia in critically ill patients: a prospective surveillance study. Mycoses 2007;50:302-10.

63 Piazza O, Boccia MC, lasiello A, et al. Candidemia in intensive care patients. Minerva Anestesiol 2003;70:63-9.

64 Wang J, Wang P, Wang X, et al. Use and prescription of antibiotics in primary health care settings in China. JAMA Intern Med 2014;174:1914-20.

65 Agrawal C, Biswas D, Gupta A, et al. Antibiotic overuse as a risk factor for candidemia in an Indian pediatric ICU. Indian J Pediatr 2015;82:530-6.

66 Cheng M-F, Yang Y-L, Yao T-J, et al. Risk factors for fatal candidemia caused by Candida albicans and non-albicans Candida species. BMC Infect Dis 2005;5:22.

67 Cheng M-F, Yu K-W, Tang R-B, et al. Distribution and antifungal susceptibility of Candida species causing candidemia from 1996 to 1999. Diagn Microbiol Infect Dis 2004:48:33-7.

68 Yang Y-L, Ho Y-A, Cheng H-H, et al. Susceptibilities of Candida species to amphotericin $B$ and fluconazole: the emergence of fluconazole resistance in Candida tropicalis. Infect Control Hosp Epidemiol 2004;25:60-4.

69 Yang Y-L, Cheng H-H, Lo H-J. In vitro activity of voriconazole against Candida species isolated in Taiwan. Int $J$ Antimicrob Agents 2004;24:294-6.

70 Chow JK, Golan Y, Ruthazer R, et al. Factors associated with candidemia caused by non-albicans Candida species versus Candida albicans in the intensive care unit. Clin Infect Dis 2008;46:1206-13.

71 Chow JK, Golan Y, Ruthazer R, et al. Risk factors for albicans and non-albicans candidemia in the intensive care unit. Crit Care Med 2008;36:1993-8. 